\title{
Economic Evaluation of Photovoltaic and Energy Storage Technologies for Future Domestic Energy Systems - A Case Study of the UK
}

\author{
Yue Wang ${ }^{\mathrm{a} 1}$, Ridoy Das ${ }^{\mathrm{b}}$, Ghanim Putrus ${ }^{\mathrm{c}}$, Richard Kotter ${ }^{\mathrm{c}}$ \\ ${ }^{a}$ Department of Engineering and \\ Design \\ University of Chichester, \\ Upper Bognor Rd, \\ Bognor Regis, \\ United Kingdom, PO21 1HR \\ ${ }^{\mathrm{c}}$ Electrical Power and Control \\ Systems research group, \\ Faculty of Engineering and \\ Environment, \\ Northumbria University, \\ Newcastle upon Tyne, \\ United Kingdom, NE1 8ST
}

\begin{abstract}
Developments in photovoltaic (PV) technologies and mass production have resulted in continuous reduction of PV systems cost. However, concerns remain about the financial feasibility for investments in PV systems, which is facing a global shrinking of government support. This work evaluates the investment attractiveness of rooftop PV installations and the impact of energy storage systems (ESS), using the UK as a case study. The evaluation considers the location of installation, the temporal evolution of the supporting policies, local energy consumption, electricity price and cost of investment at different years. Furthermore, the use of electric vehicles (EVs) as an alternative to ESS for complementing PV systems is also investigated. Optimization techniques are employed to schedule ESS and EV energy exchange in order to maximise the investment return. The results show that the net present value of PV systems in the UK has dropped from $£ 28,650$ in 2011 to $£ 1,200$ in 2017 , due to declining government support towards PV technologies. It further shows that by incorporating ESS with PV systems, the benefit in 2017 can be increased by 46\%. Conversely, employing the EV as energy storage would not bring additional benefits, considering the associated battery degradation and the current battery manufacturing cost.
\end{abstract}

Keywords: PV, energy storage, electric vehicle, feed-in tariff, net present value, non-linear optimisation.

Abbreviations:
\begin{tabular}{|ll|}
\hline DPP & Discounted payback period \\
ESS & Energy storage system \\
EV & Electric vehicle \\
FIT & Feed-in tariff \\
LCOE & Levelized cost of energy \\
NM & Net metering \\
NPV & Net present value \\
PV & Photovoltaic \\
V2H & Vehicle to home \\
\hline
\end{tabular}

\section{Nomenclature:}

\begin{tabular}{|ll|}
\hline$a_{1}, a_{2}$ & Fitting parameters of battery degradation cost \\
$C_{P V_{-} M}$ & Annual maintenance cost of PV system \\
$C_{i n v}$ & Investment cost \\
$c_{E V}$ & EV battery degradation cost \\
$C_{P V_{-} E S S}$ & Daily operational cost for PV+ESS \\
$C_{P V_{-} E V}$ & Daily operational cost for PV+EV \\
$C F$ & Annual cash flow \\
\hline
\end{tabular}

\footnotetext{
${ }^{1}$ Corresponding author, Department of Engineering and Design, University of Chichester, Upper Bognor Road, Bognor Regis, PO21 1HR. yue.wang@chi.ac.uk
} 


\begin{tabular}{|ll|}
\hline$C F_{P V}$ & Annual cash flow for PV \\
$C F_{P V_{-} E S S}$ & Annual cash flow for PV+ESS \\
$C F_{P V_{-} E V}$ & Annual cash flow for PV+EV \\
$D$ & Number of days in a year \\
$d$ & Day index in a year \\
$E_{E S S}$ & Instantaneous energy stored in the ESS \\
$E_{E S S O}$ & Initial energy stored in the ESS \\
$E_{E S S_{-} M A X}$ & Maximum energy allowed to be stored in the ESS \\
$E_{E S S_{-} M I N}$ & Minimum energy allowed to be stored in the ESS \\
$E_{E V}$ & Instantaneous energy stored in the EV \\
$E_{E V 0}$ & Initial energy stored in the EV \\
$E_{E V_{-} M A X}$ & Maximum energy allowed to be stored in the EV \\
$E_{E V_{-} M I N}$ & Minimum energy allowed to be stored in the EV \\
$E_{P V}$ & Annual PV energy production \\
$\varepsilon$ & EV availability \\
$F I T_{e x p}$ & Export FIT tariff \\
$F I T_{g e n}$ & Generation FIT tariff \\
$i$ & Year index in the investment lifetime \\
$N$ & Investment lifetime in years \\
$P_{B L}$ & Baseload power profile \\
$P_{E S S}$ & ESS exchange power profile \\
$P_{E S S_{-} M A X}$ & Maximum charging rate of ESS \\
$P_{E S S_{-} M I N}$ & Minimum charging rate of ESS \\
$P_{E V}$ & EV exchange power profile \\
$P_{E V \_M A X}$ & Maximum charging rate of EV \\
$P_{E V \_M I N}$ & Minimum charging rate of EV \\
$P_{P V}$ & PV generation power profile \\
$p_{e}$ & Utility electricity price \\
$R_{F I T}$ & Annual revenue from FIT \\
$r$ & Discount rate \\
$S_{P V}$ & Annual savings in operational cost for PV \\
$S_{P V_{-} E S S}$ & Annual savings in operational cost for PV+ESS \\
$S_{P V_{-} E V}$ & Annual savings in operational cost for PV+EV \\
$T$ & Total time steps in a day \\
$t$ & Time index in a day \\
$\Delta t$ & Duration of each time step \\
&
\end{tabular}

\section{Introduction}

Renewable energy sources are expected to continue to-grow over the next decades, with the sector boosted by falling costs of wind and solar systems [1]. In fact, by the end of 2017, 179 countries around the world had set renewable energy targets at national or regional level, backed by government incentives to support and promote the deployment of renewable energy [2]. Among different forms of government support, feed-in tariff (FIT) is the most popular renewable energy supporting mechanism, which has been adopted by 84 countries as of the end of 2017 [2].

The generous incentives from FIT contributed to the increase in domestic renewable installations. However, the cutbacks in government support on FIT in recent years, in various countries such as Germany [3], Australia [4], and the UK [5], have made investors more cautious about investment in domestic renewable energy [6]. In particular, the drop in supporting policies has affected photovoltaic (PV) systems, which are among the most attractive distributed generators due to their easy application 
and maintenance [7]. Consequently, there is a real need to investigate the financial profitability of PV investment.

The viability of investment in PV systems have been widely analysed for different sectors, including residential and workplace, in different countries and regions, such as Iran [7], Australia [8], Flanders [9], UK [10], [11], Germany [12], [13], New Zealand [14], and India [10]. The PV investment is shown to be in general economically viable in these countries, whereby the most influential parameters are identified to be the capital cost of investment, solar irradiation, and the local/regional supporting policy. The associated economic evaluations were carried out using combinations of these parameters, or via sensitivity analyses for certain parameters of interest.

The analysis for Flanders, Belgium, carried out in [9] showed that the revenue of the investment mainly originated from subsidies and supporting policy. The cost-benefit analysis in [10] demonstrated the profitability of the domestic PV investment in different cities in the UK and India. It was shown that a domestic PV system in India added value to the house owner only when generation FIT was considered. In contrast, the authors showed that investment in domestic PV systems since 2012 in London was not always viable, even with the FIT for both generation and export. The work in [10] also pointed out that the location specific PV system planning could be improved by optimising PV sizes, although the latter was not addressed. The case study for Australia [8] demonstrated that domestic PV systems with small installed capacity proved to be more viable options for investors compared to larger PV-energy storage systems. A new FIT scheme was proposed for Iranian cities in [7], however, the results presented showed that without any subsidy, the LCOE of PV systems was higher than the electricity price.

Energy storage systems (ESS) employed with domestic PV systems have been investigated in [12], which was shown to be economically viable by self-consumption of the PV production and participating in the wholesale electricity market. The techno-economic feasibility of second life EV batteries was analysed in [15] for integration with a residential PV system. The results showed that smaller batteries provided a higher and faster return of investment, however the optimal sizing of PV-ESS system and optimal ESS scheduling were not investigated.

The authors in [16] investigated the profitability of the Tesla Powerwall with a residential PV system for different electricity prices, subsidy schemes, battery ageing and electricity demand levels. The authors found that investment in battery storage was only marginally profitable without subsidies. A series of scenario analyses were presented in [17] for various sizes and combinations of PV-ESS systems. The study showed that the presence of subsidy and substantial increase in self-consumption enabled by energy storage are the key for the economic viability of PV integrated battery systems.

Similarly, the authors in [8] and [11] showed that it was possible to achieve a higher return of investment by reducing the net energy imported from the grid through appropriate use of ESS with local PV generation. In contrast with the previous work, the evaluation in [8] demonstrated that ESS did not bring additional economic benefit to the existing PV system, due to the high capital cost of ESS. The same conclusions were drawn for a typical 3-bedroom house in the midland in UK [11], where the financial loss due to ESS was attributed to the inadequate control strategy as well as the inherently poor efficiency of ESS.

As EV uptake continues to increase, EV batteries can be used as an alternative to ESS for supporting PV systems in order to obtain energy self-sufficiency as well as better return on investment on both PV and EV. An investment analysis for a combination of a commercial PV system and multiple EVs was carried out in [18], which proved that more benefits can be gained by the combined PV-EV system than the individual technologies alone. A number of case studies on the integration of PV and EV systems are available in the literature [19] [20] [21] [22], where EV batteries were used for load balancing in order to maximise the overall profit. However, no conclusive results were presented on the return of investment. The work in [23] evaluated the synergy between residential PV systems, energy storage 
and EVs. The results showed that the economic viability of the PV system highly depends on the subsidies on renewable energy.

In addition, an emerging technology of on-board PV systems integrated with EVs has been explored in [24] and [25], with the aim to increase the efficiency of the transportation system. The former highlighted the benefits of the daily mileage increase and daily $\mathrm{CO}_{2}$ emissions reduction brought by the on-board PV systems. The latter evaluated and quantified the dependency of economic viability of such systems on the electricity price and irradiation level. However, the focus of the research presented in this paper is on residential PV systems, and therefore on-board PV systems are beyond the scope of this research.

It is important to note that the most commonly used economic criteria include net present value (NPV), discounted payback period (DPP), and levelized cost of energy (LCOE). Compared to LCOE, the NPV and DPP are more effective in indicating the economic feasibility of the prospective investment [8]. For example, the work presented in [14] showed that the LCOE of PV system is higher than the electricity price, whilst the NPV showed that it is viable to invest in PV by considering the FIT. As a result, in this present study, we adopt the NPV and DPP as economic measures for the associated financial evaluations.

However, none of the work mentioned earlier considered the temporal evolution of the supporting policy, the associated energy consumption, electricity price and cost for investment at different years with various installation capacities of PV and ESS. All these factors have been considered simultaneously in this work by carrying out a comprehensive economic evaluation of rooftop PV installations as well as the combined PV and the battery storage systems. The impact of diverse solar irradiation levels has also been assessed here with different geographical locations. Additionally, the economic viability of PV systems combined with ESS, stationary and mobile in electric vehicles (EVs), has also been analysed for potentially better financial return.

In particular, EVs will play a prominent role in future domestic energy systems due to their massive deployment. EVs have therefore been investigated for the first time as an alternative to stationary ESS, in combination with domestic PV systems. To this end, the vehicle usage patterns have been extracted from survey data and the extra EV battery cycling due to the household smart energy management are quantified by a battery degradation model. A non-linear optimisation approach is employed to maximise the return of investment by smart scheduling of energy exchange of ESS and EV battery. Based on the financial assessment of different household energy scenarios, namely PV, PV+ESS and PV+EV, the optimal sizing under each scenario is then presented. The proposed method is applied to the UK case study as it is one of the world leading countries that show significant reduction in FIT rate.

The novelty and main contributions of this work can be summarised as follows from the economic and social aspects:

- The extensive literature review conducted here shows that the economic evaluation of combined PV, ESS and EV systems have not been modelled and compared in the same context, depth and presented substantiated results and conclusions as in the research presented in this paper. The economic feasibility and optimal sizing of these three elements combined have been investigated for the first time by implementing optimal charging/discharging scheduling.

- None of the work published so far has considered together the temporal evolution of the FIT rate, investment cost for different technologies, annual consumption, electricity price and the change in solar irradiation due to spatial variation. All these factors have been considered in this work by carefully cross-checking with reliable data sources. Additionally, real-life EV travel patterns have been used to model the interaction between the EV and PV system to present a realistic analysis. 
- Previous work [7], [9], [10], [13], and [14] used cumulative annual or monthly figures of PV generation and household demand profiles. This paper makes use of high-resolution (15 minutes) real data that cover all seasons and days in a year, with an optimisation algorithm applied to determine the energy scheduling of ESS and EV aiming to optimise the return of investment.

- The proposed economic model accurately depicts the rising and falling of the return rate of PV systems in the UK, which have been validated by the actual annual PV installation data for the same period.

Following a literature review and positioning the contribution of this paper presented in this section, an outline of the rest of the paper is as follows. In the next section, the economic measures for evaluation of investment are defined, and the problems of optimal return of investment are also formulated for the scenarios of PV, PV+ESS and PV+EV. The case study in the UK is presented in Section 3, whereby economic feasibility of domestic PV investment is evaluated for different UK locations, years and sizes of installation. The viability of using stationary and mobile ESS, to compensate the reducing profit margin from PV system is assessed in Sections 4 and 5, respectively. Conclusions are presented in Section 6.

\section{Methodologies for return on investment}

The NPV and DPP are used to evaluate the investment attractiveness for various domestic installations incorporating PV, ESS and EV.

The NPV provides the current monetary value of a potential investment project by converting the yearly cash flow throughout its lifetime to the present value using a discount rate. An investment with a positive NPV will be economically viable, whereas a negative NPV indicates an investment with a net loss [26]. The NPV is defined by Equation (1):

$N P V=\sum_{i=1}^{N} \frac{C F(i)}{(1+r)^{i}}-C_{i n v}$

where $r$ is the discount rate, which is used for the present value conversion during its lifetime of $N$ years; $C_{i n v}$ is the initial investment cost; $C F(i)$ is the net $i^{\text {th }}$ year cash inflow, with net profit being positive and net cost being negative.

The DPP is the required number of years to achieve break-even for a given investment cost, $C_{i n v}$, yearly cash flow, $C F(i)$, and the discount rate, $r$, [26]. The DPP is therefore the solution of Equation (1) for $N$ by setting NPV to zero. In other words, a project with positive NPV implies that the investment can be recovered within the project lifetime, and vice versa.

It can be seen from Equation (1) that, given a certain investment cost, the NPV of a project can be optimised by maximizing its yearly cash flow. In the following sections, the cash flow $C F(i)$ endowed with the subscripts PV, PV_ESS and PV_EV, i.e. $C F_{P V}(i), C F_{P V_{-} E S S}(i), C F_{P V_{-} E V}(i)$, will be employed to denote the cash flows associated to PV, PV plus ESS and PV plus EV, respectively. And the investment cost, $C_{i n v}$, covers the capital cost for the associated components.

\subsection{Investment of $P V$}

In this case, the base demand can be supplied by the PV generation and the associated savings in energy cost is therefore achieved. The yearly cash flow associated with $\mathrm{PV}, C F_{P V}(i)$, as expressed in Equation (2):

$$
C F_{P V}(i)=S_{P V}(i)+R_{F I T}(i)-C_{P V \_}(i)
$$


Where $S_{P V}(i)$, as expressed in Equation (3), is the annual savings achieved in the $i^{\text {th }}$ year from energy cost reduction due to local consumption from solar generation, $R_{F I T}(i)$ is the $i^{\text {th }}$ yearly revenue gained from FIT, and $C_{P V_{-} M}(i)$ is the annual PV maintenance cost in the $i^{t h}$ year.

$$
S_{P V}(i)=\sum_{d=1}^{D}\left\{\sum_{t=1}^{T} P_{B L}(i, d, t) \Delta t p_{e}(i, d, t)-c_{P V}(i, d)\right\}
$$

The first lumped term in Equation (3) indicates the daily energy cost of the baseline when there is no consumption from local PV generation, where $P_{B L}(i, d, t)$ and $p_{e}(i, d, t)$ are the domestic baseload profile and electricity price, respectively, at the $t^{\text {th }}$ time instant within the $d^{\text {th }}$ day and of the $i^{\text {th }}$ year. $\Delta t$ is the duration for the sampling time step, and $D$ and $T$ are the number of days and total time steps, respectively. The convention of the indices of $i, d, t$ will be adopted hereafter in this paper.

The second term in Equation (3), $c_{P V}(i, d)$, is the daily energy cost with local consumption from PV generation, as expressed in Equation (4), where $P_{P V}(i, d, t)$ describes the PV generation profile. The plus sign ' + ' in the superscript means that only the positive values of the net power exchange are considered. The convention of this superscript is used thereafter in this work.

$c_{P V}(i, d)=\sum_{t=1}^{T}\left[P_{B L}(i, d, t)-P_{P V}(i, d, t)\right]^{+} \Delta t p_{e}(i, d, t)$

The revenue from FIT, $R_{F I T}(i)$, is due to both generation and export, as shown in Equation (5),

$R_{F I T}(i)=F I T_{g e n} \sum_{t=1}^{T} P_{P V}(i, d, t) \Delta t+F I T_{\text {exp }} \sum_{t=1}^{T}\left[P_{P V}(i, d, t)-P_{B L}(i, d, t)\right]^{+} \Delta t$

where $F_{\text {I }}$ gen and FIT $_{\text {exp }}$ are the generation tariff and export tariff, respectively.

\subsection{Investment on PV and ESS}

Unlike the previous section, where PV generation is passively coordinated with the demand profile, the additional ESS can be controlled to increase the utilisation of local renewable generation to supply the household demand and hence maximizing the potential return on investment. The objective as such is to maximize the yearly cash flow of PV installation with the aid of ESS, $C F_{P V_{-} E S S}(i)$, as expressed in Equation (6),

$\max C F_{P V_{-} E S S}(i)=S_{P V_{-} E S S}(i)+R_{F I T}(i)-C_{P V_{-} M}(i)$

where the difference with Equation (2) is due to the annual savings in energy cost in the $i^{\text {th }}$ year, $S_{P V_{-} E S S}(i)$. Similar to Equation (3), this saving figure can be calculated based on the difference in daily energy cost between the baseline and the case with PV and ESS installation, the latter of which is obtained from Equation (7).

$c_{P V_{-} E S S}(i, d)=\sum_{t=1}^{T}\left[P_{B L}(i, d, t)-P_{P V}(i, d, t)+P_{E S S}(i, d, t)\right]^{+} \Delta t p_{e}(i, d, t)$

The additional term in Equation (7) compared with Equation (4) is the scheduling of ESS, $P_{E S S}(i, d, t)$. The optimisation problem shown in Equation (6) is subject to the constraints in Equation (8).

$\begin{cases}P_{E S S_{-} M I N} \leq P_{E S S}(i, d, t) \leq P_{E S S_{-} M A X}, & \forall d, t \\ E_{E S S_{-} M I N} \leq E_{E S S}(i, d, t) \leq E_{E S S_{-} M A X}, & \forall d, t\end{cases}$

The ESS scheduling profile $P_{E S S}(i, d, t)$ is variable and confined within the lower and upper bound of $P_{E S S_{-} M I N}$ and $P_{E S S_{-} M A X}$ respectively. The energy stored in ESS, $E_{E S S}(i, d, t)$, is defined by Equation (9),

$\left\{\begin{array}{lr}E_{E S S}(i, d, t)=E_{E S S}(i, d, t-1)+P_{E S S}(i, d, t) \Delta t & d>0, t>0 \\ E_{E S S}(i, 1,0)=E_{E S S} & d>1\end{array}\right.$ 
where $E_{E S S 0}$ is the initial energy status of ESS on the first day and the initial ESS values for the following days in a year is set to be the final ESS state of the previous day. The energy stored in ESS also needs to be within the capacity limit of $\left[E_{E S S_{-} M I N}, E_{E S S_{-} M A X}\right]$.

\subsection{Investment on $P V$ and $E V$}

As EV uptake continues to increase, its integrated battery could participate in household energy management when being parked. This section investigates the EV battery as an alternative to ESS for complementing the PV systems by formulating the optimal return on investment on PV and EV. In this case, it is assumed that the capital cost of EV is part of the transportation investment and therefore does not contribute to the NPV calculation of the energy solution investment. However, the battery degradation cost per $\mathrm{kWh}$ of throughput is considered as cost of use, and the capital cost for bidirectional charger will be taken into account as part of the investment on PV and EV.

Similar to the optimisation problem defined in Section 2.2, the optimisation target here is to maximize yearly cash flow, $C F_{P V_{-} E V}$ as expressed in Equation (10), by coordinating PV generation with EV battery energy scheduling.

$\max C F_{P V_{-} E V}(i)=S_{P V_{-} E V}(i)+R_{F I T}(i)-C_{P V_{-} M}(i)$

The annual savings in energy cost, $S_{P V_{-} E V}(i)$, is calculated based on the daily operational cost for coordinated PV and EV, $c_{P V_{-} E V}(i, d)$ as expressed in Equation (11), following similar method as shown in Equation (3). $R_{F I T}$ and $C_{P V_{-} M}$ retain the same meaning as in Equations (2) and (6).

$$
\begin{aligned}
& c_{P V_{-} E V}(i, d)=\sum_{t=1}^{T}\left\{\left[P_{B L}(i, d, t)-P_{P V}(i, d, t)+P_{E V}(i, d, t) \varepsilon(i, d, t)\right]^{+} \Delta t p_{e}(i, d, t)+\right. \\
& \left.\left|P_{E V}(i, d, t) \varepsilon(i, d, t)\right| \Delta t c_{E V}(i, d, t)\right\}
\end{aligned}
$$

where $P_{E V}(i, d, t)$ represents the EV scheduling profile, $\varepsilon$ is the EV availability (1 for being available and 0 for otherwise) and $c_{E V}$ is the battery degradation cost per $\mathrm{kWh}$ of energy throughput due to coordination with PV generation and household demand. The remaining parameters in Equation (11) retain the same meaning as in Equation (7). Unlike the case of ESS, where the investment cost is included in the NPV calculation, the capital cost of EV as well as the battery degradation due to transportation is not considered here. The extra battery degradation cost, $c_{E V}$, due to energy exchange with PV generation and household demand, exhibited linear dependence on the charging/discharging rate [27]. Such linear relationship is expressed in Equation (12), where $a_{1}$ and $a_{2}$ are fitting parameters for the empirical battery degradation model.

$c_{E V}(i, d, t)=a_{1}\left|P_{E V}(i, d, t)\right|+a_{2}$

The optimisation problem defined in this section is subject to the constraints in Equation (13),

$\begin{cases}P_{E V \_M I N} \leq P_{E V}(i, d, t) \leq P_{E V \_M A X}, & \forall d, t \\ E_{E V \text { MIN }} \leq E_{E V}(i, d, t) \leq E_{E V \_M A X}, & \forall d, t\end{cases}$

where the EV scheduling profile $P_{E V}(i, d, t)$ is variable and bounded within the range of $\left[P_{E V-M I N}\right.$, $\left.P_{E V \_M A X}\right]$. The energy stored in EV, $E_{E V}(i, d, t)$, as expressed in Equation (14), also needs to be within the capacity limit, [ $\left.E_{E V_{-} M I N}, E_{E V_{-} M A X}\right]$. Given the initial energy status of $\mathrm{EV}$ on the first day, $E_{E V 0}$, the initial ESS values for the following days in a year is set to be the final value of the previous day.

$$
\left\{\begin{array}{lr}
E_{E V}(i, d, t)=E_{E V}(i, d, t-1)+P_{E V}(i, d, t) \Delta t & d>0, t>0 \\
E_{E V}(i, 1,0)=E_{E V 0} & d>1
\end{array}\right.
$$

\section{Economic viability of domestic PV systems}


In this section, the financial attractiveness for household PV investment at different geographical locations is investigated by considering the UK as a case study. As mentioned previously, the temporal evolution of economic feasibility is evaluated for domestic PV installation up to $6 \mathrm{~kW}$, by taking into account the evolution for FIT rate, the cost of PV, household demand and associated electricity price, as well as PV generation profile.

\subsection{Evolution of FIT in the UK}

In the context of the UK, most domestic renewable and low carbon electricity-generating technologies, such as solar photovoltaic (PV) and wind turbines with an installed capacity of $5 \mathrm{MW}$ or less, qualify for the FIT scheme, introduced in 2010, [28]. The following incentives were given to individuals who were eligible to receive FIT payments [28]:

1) Generation tariff: a set rate for each kWh of electricity generated is paid by the energy supplier. Once the system has been registered, the tariff levels are guaranteed for the period of the tariff up to 20 years.

2) Export tariff: The energy supplier pays a further rate for each $\mathrm{kWh}$ exported back to the electricity grid. An export meter needs to be installed to measure the actual export to the grid; however, this is only required for systems above $30 \mathrm{kWp}$. Households in the UK are unlikely to install PV systems of this size and above; they are therefore deemed to be exporting $50 \%$ of the electricity generated regardless of what their actual export capacity is [29].

On top of the FIT, savings from the energy bill could also be achieved by powering the appliances using local renewable generation. The amount saved as such will depend on the degree of energy autonomy on site.

In this work, domestic PV systems up to $6 \mathrm{~kW}$ are explored. The associated grid connections are in compliance with the GB Distribution Code for small scale embedded generation systems, i.e. G83/G98 for connections of up to $3.7 \mathrm{~kW}$ per phase and $11 \mathrm{~kW}$ for three-phase connections [30]. The temporal evolution of FIT rates are illustrated in Figure 1, which shows that the export rate stayed at almost the same level since it was introduced in April 2010, whereas the generation tariff is drastically reduced during the same period, with slight higher rates for $0-4 \mathrm{~kW}$ installation capacity compared to $4-10 \mathrm{~kW}$ from year 2012 to 2015. The continuous drops in the FIT rate was driven by the falling cost of the PV systems, due to technology advancement and mass production. The PV system installation cost, including the cost of PV module, inverter, labour and VAT is shown in Figure 1 by the dashed line and it can be seen that its value as of 2017 was less than half of what it was in 2010.

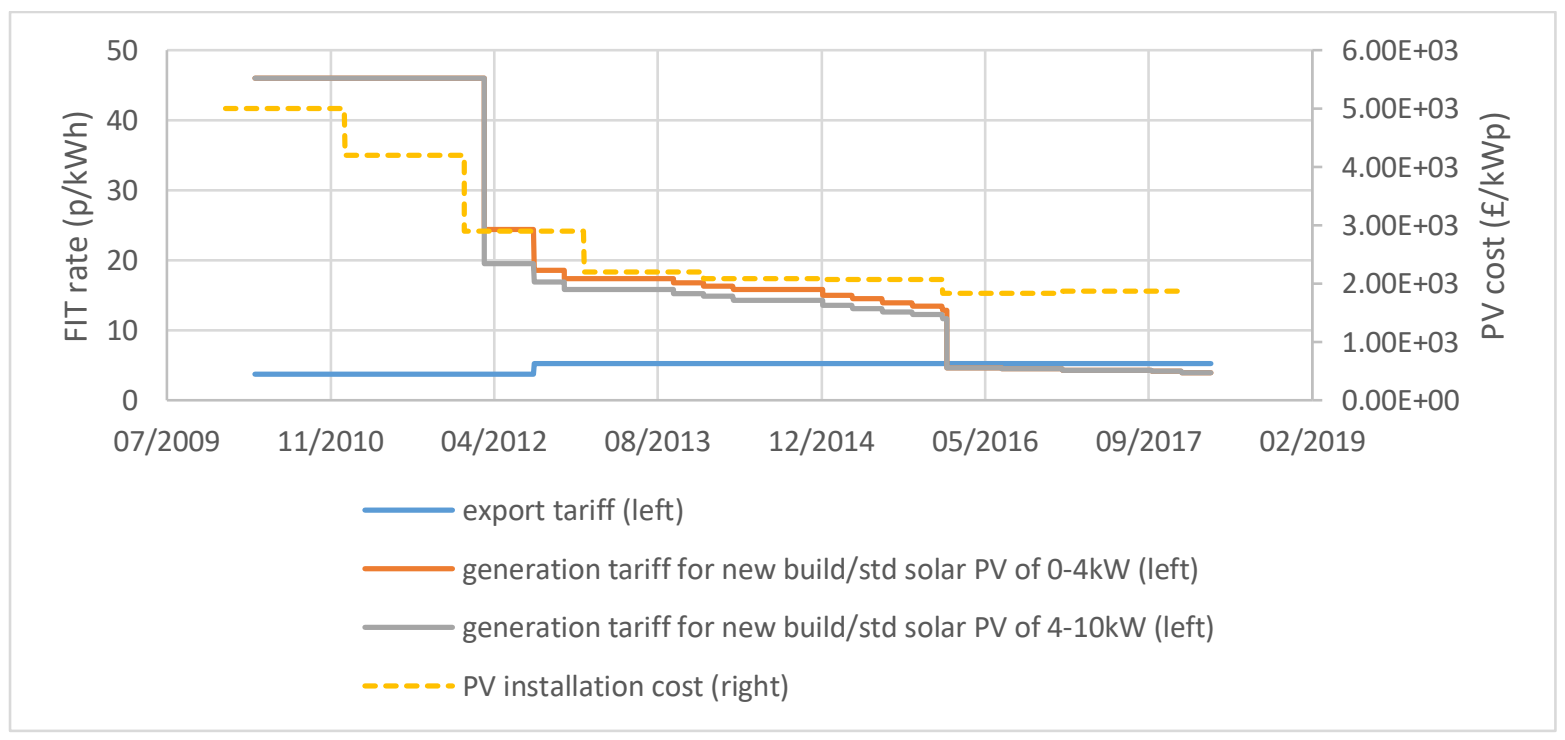




\subsection{PV generation profile for the selected locations in the UK}

PV generation profile for a given PV installation is proportional to the associated solar irradiation level, which varies significantly across the UK [33]. In this study, three locations in the UK with different annual solar generation profiles per $\mathrm{kW}$ of $\mathrm{PV}$ installation were selected for the analysis. These are Fort William from the northwest of Scotland (with the lowest annual irradiance), Nottingham from the Midlands (a medium level of annual irradiance), and Brighton from the south of England (with the highest annual irradiance), as shown in Figure 2. It can be seen from Table 1 that the annual unit PV generation of $1100 \mathrm{kWh}$ for Brighton almost doubles that from Fort William, and Nottingham sits in the middle of this range.

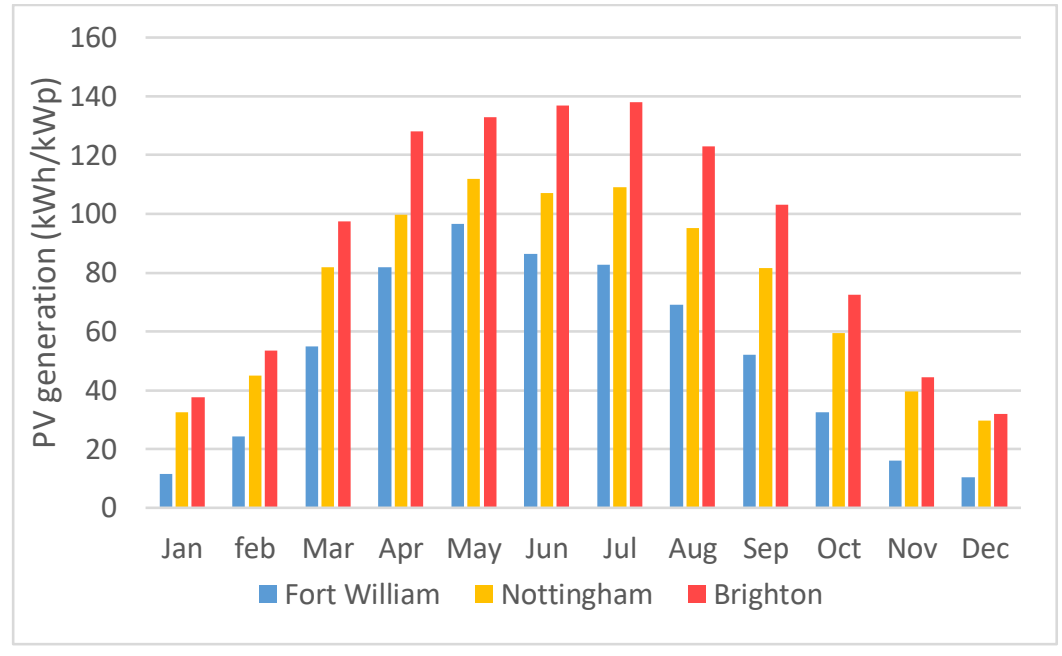

Figure 2: Monthly PV generation profile for three selected locations in the UK [34]

Table 1: Annual unit PV generation profile for three selected locations in the UK

\begin{tabular}{ll}
\hline Locations & Annual PV generation $(\mathrm{kWh} / \mathrm{kWp})$ \\
\hline Fort William & 619 \\
Nottingham & 894 \\
Brighton & 1100 \\
\hline
\end{tabular}

\subsection{Financial evaluation of $P V$ investment}

In this work, a data resolution of 15 minutes is used for the analysis, namely for the PV generation profile, the energy consumption profile, and in later sections for the scheduling of ESS and EV battery power exchange profiles. This indicates a total time frame, $T$, of 96 , with a step, $\Delta t$, of $1 / 4$ hours, for each day in a year $(D=365)$. A typical household demand profile in the UK is adopted for the analysis, covering all seasons and all days in a year, although the time series of these profiles are not presented in this work for the purpose of being concise.

In addition to the temporal evolution of the FIT and investment cost of the PV system, Figure 3 depicts the yearly evolution of a typical household demand in the UK. In this case study, a flat domestic electricity tariff is adopted, and its yearly increments is shown alongside the annual consumption in Figure 3.

According to the problem formulation in the Section 2, the temporal and spatial investment attractiveness for domestic PV installation are evaluated since when the FIT was first introduced in

\footnotetext{
${ }^{2}$ The tariff for houses with EPC of level D or above is used here. This is also known as the Higher tariff band, which is different from the Middle and Lower tariff.
} 
2010. The PV lifetime is assumed to be 20 years, i.e. the entire lifetime is eligible for FIT, and an annual discount rate of $2 \%$ is utilized in this work [10]. The lifetime of PV converter is assumed the same as the PV system as there are no relevant studies yet on this specific topic to the best knowledge of the authors. The annual PV maintenance cost is assumed to be $18 \mathrm{f} / \mathrm{kWp}$ as per [38], that is the maintenance cost per kW of PV peak or maximum installed capacity for each year of its lifetime. As mentioned earlier, 50\% of PV generation in the UK is assumed to be exported to the grid regardless of the actual grid exchange.

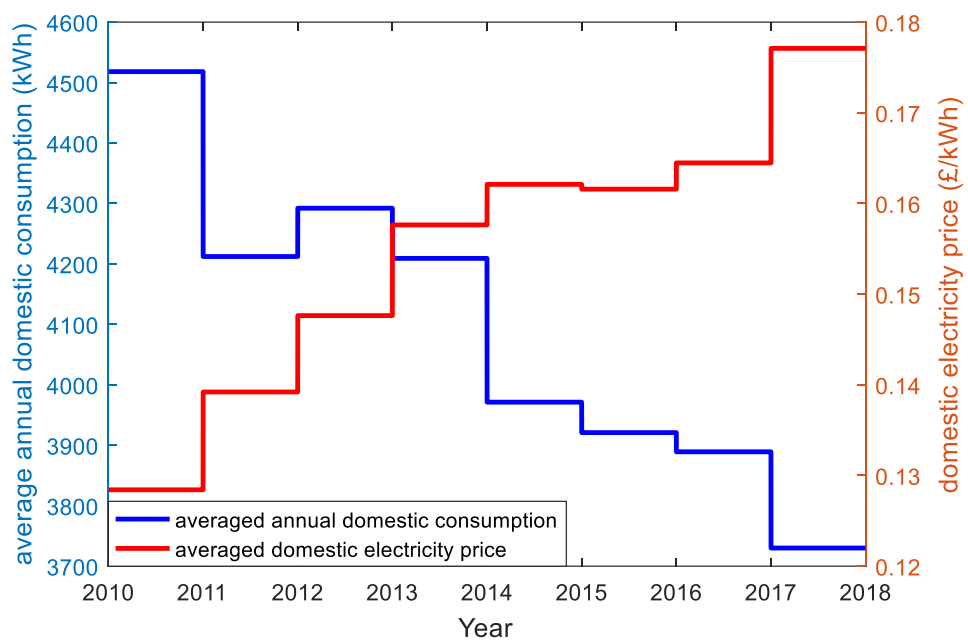

Figure 3: Evolution of annual domestic consumption [35] [36] alongside electricity tariff [37]

The evolution of NPV and DPP for domestic PV investment for the three selected UK locations are presented in Figure 4 and Figure 5 respectively, for installation size ranging from $1 \mathrm{~kW}$ to $6 \mathrm{~kW}$. It can be observed by comparing Figure 4 with the generation tariff in Figure 1 that the FIT rate dominates the overall economic return for PV investment, showing an overall decreasing trend; in particular, for higher installation sizes. For example, the two significant drops of NPV for all three cases in 2012 and at the beginning of 2016 were due to the corresponding drops in FIT. The falling in FIT is driven by the PV cost reduction, which, however, is not sufficient to compensate the drop of benefit from FIT. This explains the negative NPV since 2016 for most PV sizes at the three locations.

The overall economic return of the three locations also vary a lot case by case, indicating the importance of considering natural (solar) resources when planning PV investments. Taking the most promising installation year of 2011 for example, the NPV varies from $£ 5356$ for Fort William, $£ 18630$ for Nottingham, to $£ 28650$ for Brighton, all of which correspond to an installation size of $6 \mathrm{~kW}$. The return of investment for locations like Fort William, which has the lowest solar irradiation in the UK, has been shown to highly rely on the financial policy support. Only limited PV sizes in this case are profitable, even when the FIT rate was relatively generous. Investment for Fort William or similar locations are demonstrated to be financially unviable since 2016. On the other hand, Nottingham and Brighton, which represent areas with average and highest solar resources respectively, were much better off in terms of overall return compared to the northwest of Scotland, even though higher PV sizes became economically unviable from 2016 onwards.

As a matter of fact, the periodic review of FIT that was carried out by the UK's Department for Energy and Climate Change at the end of 2015 has stated the government's intention to bring forward wellsited projects [39]. In other words, the adjustment of FIT price that took effect since 2016 was to support PV installation for areas with reasonable to abundant level of solar irradiation.

The discounted payback period for these three locations are shown in Figure 5, where investments are financially feasible with return period less than the project lifetime, 20 years in this case. Brighton 
almost halved the return period of Fort William for certain years, such as 2011. The DPP after 2016, as observed in Figure 5, again justifies the reluctance of domestic PV investment, in particular for areas in the north.
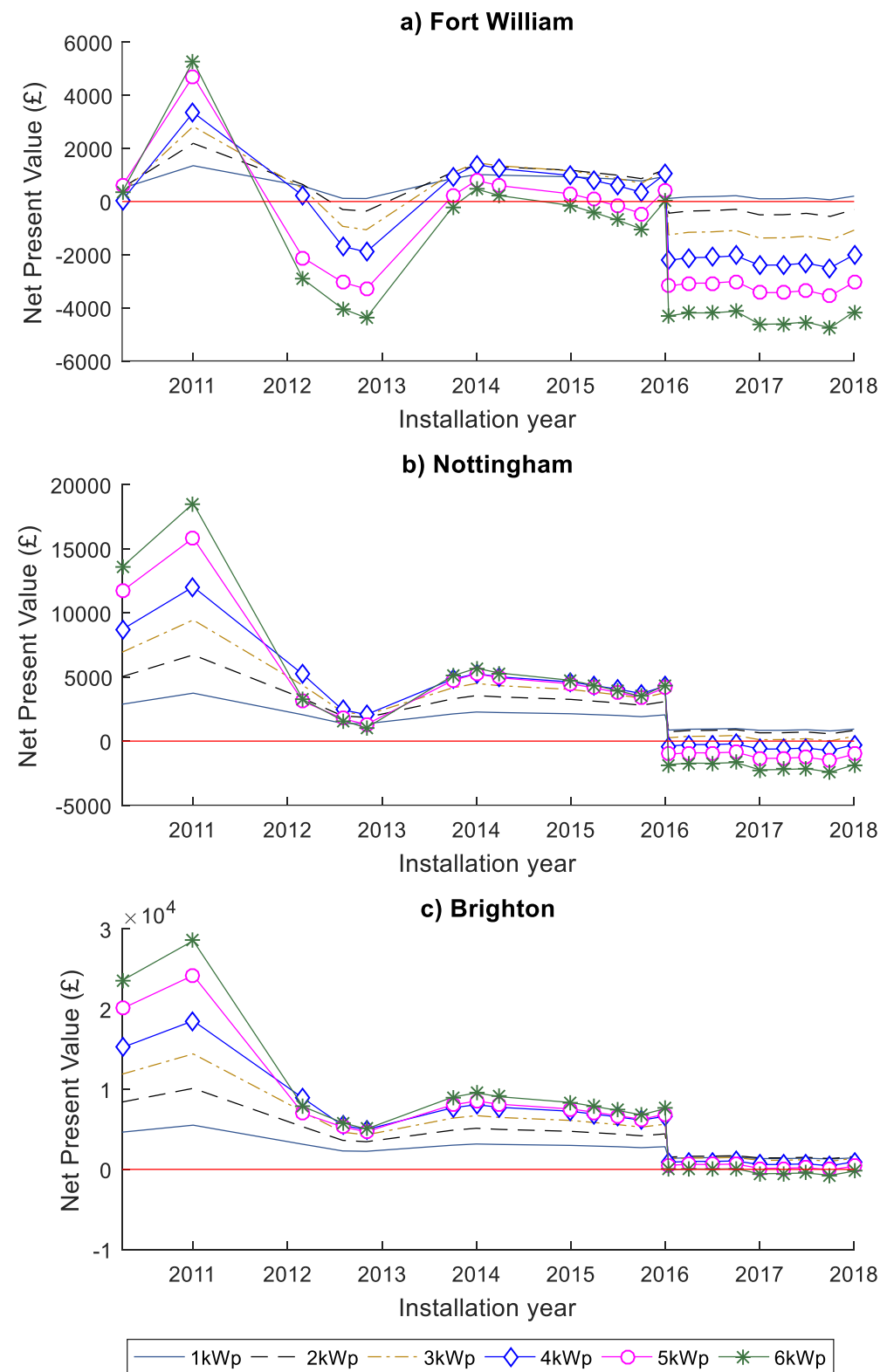

Figure 4: Evolution of NPV for domestic PV investment at three locations in the UK 

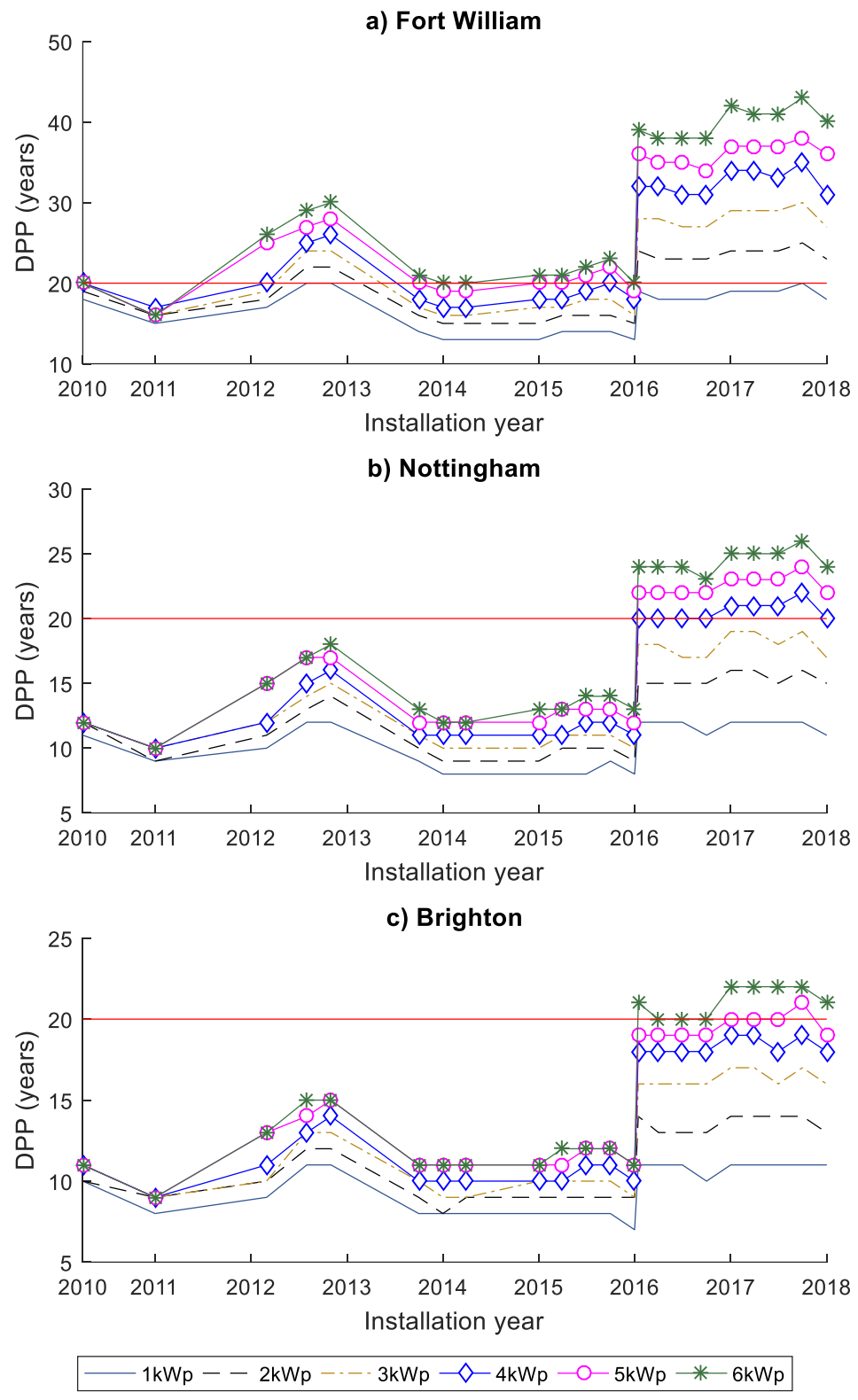

Figure 5: Evolution of DPP for domestic PV investment at three locations in the UK 


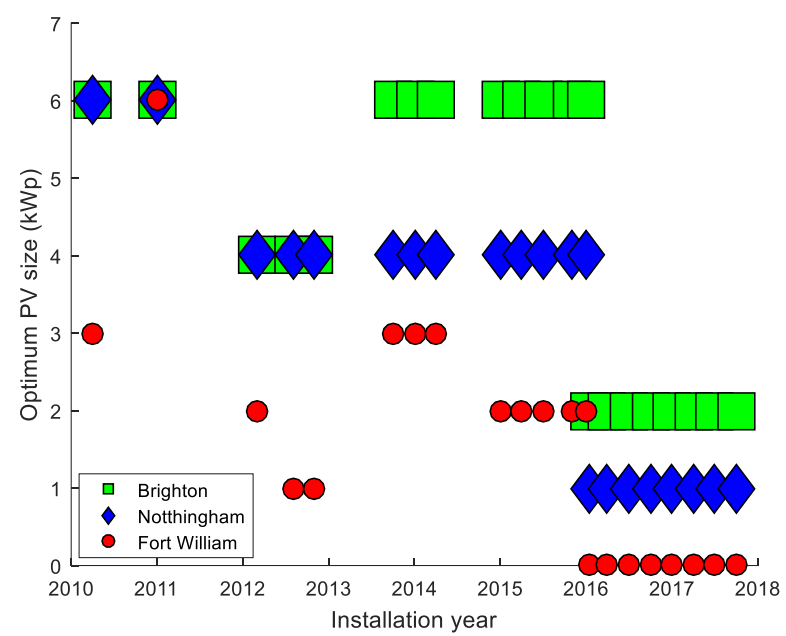

Figure 6: Optimal PV sizing

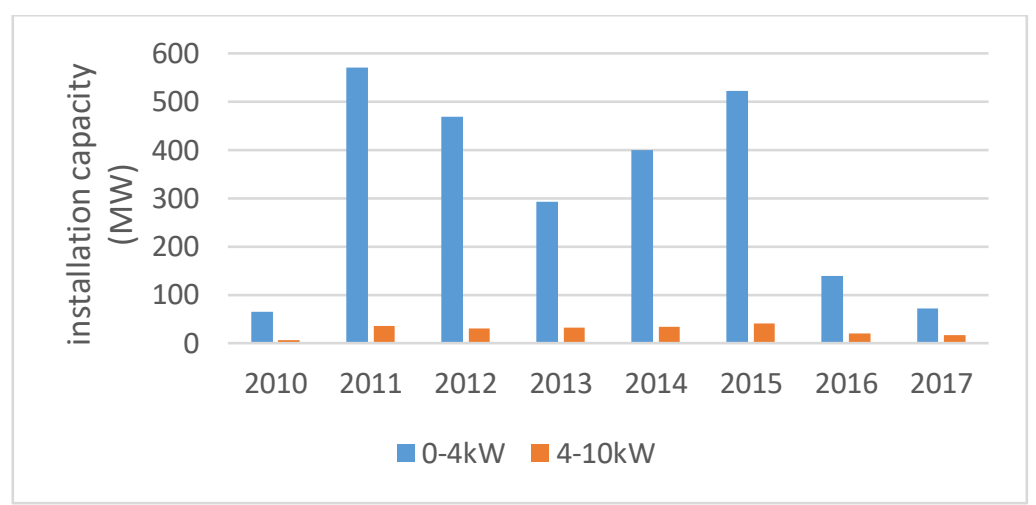

Figure 7: Yearly installation capacity of PV in the UK [40]

The optimal PV sizes of each location for different years are illustrated in Figure 6, where Brighton has been favourable towards $6 \mathrm{~kW}$ before 2016. Nottingham switched from $6 \mathrm{~kW}$ to $4 \mathrm{~kW}$ in April 2012 since separate tariffs was introduced for PV installation capacity above and below $4 \mathrm{~kW}$. Fort William mainly favoured lower PV capacity.

Figure 7 illustrates the actual PV deployment for each year in the UK, which verifies the trend of PV investment return evaluated in this section. Using the deployment number for $0-4 \mathrm{~kW}$ for instance, the deployment peak in 2011 corresponded to the summit of NPV in Figure 4. From 2011 onward, the annual installation capacity was generally above $400 \mathrm{MW}$, apart from 2013 when a dip could be observed in the NPV. Finally, the slump of NPV in 2016 justifies the refrained domestic PV investment accordingly. It could also be seen from Figure 7 that installations below $4 \mathrm{~kW}$ are much more popular than those between $4 \mathrm{~kW}$ and $10 \mathrm{~kW}$.

\subsection{Sensitivity analysis of discount rate}

Discount rate has been identified as one of the impacting factors in various works, such as [9], [10], and [12], alongside other parameters that affect the NPV evaluation. The previous section has demonstrated the impact of temporal and spatial variation of different relevant factors, and a sensitivity analysis of the discount rate is presented here to improve the comprehensiveness of this work. Discount rate of $4 \%$ and $6 \%$ are used to cover the typical range of rates, and the corresponding results are shown in Figure 8 , which is comparable to Figure 4 with applied discount rate of $2 \%$. It can be seen that the viable PV sizes decrease for each year as the discount rate rises, and Fort William become completely unviable to invest with discount rate of $6 \%$. 

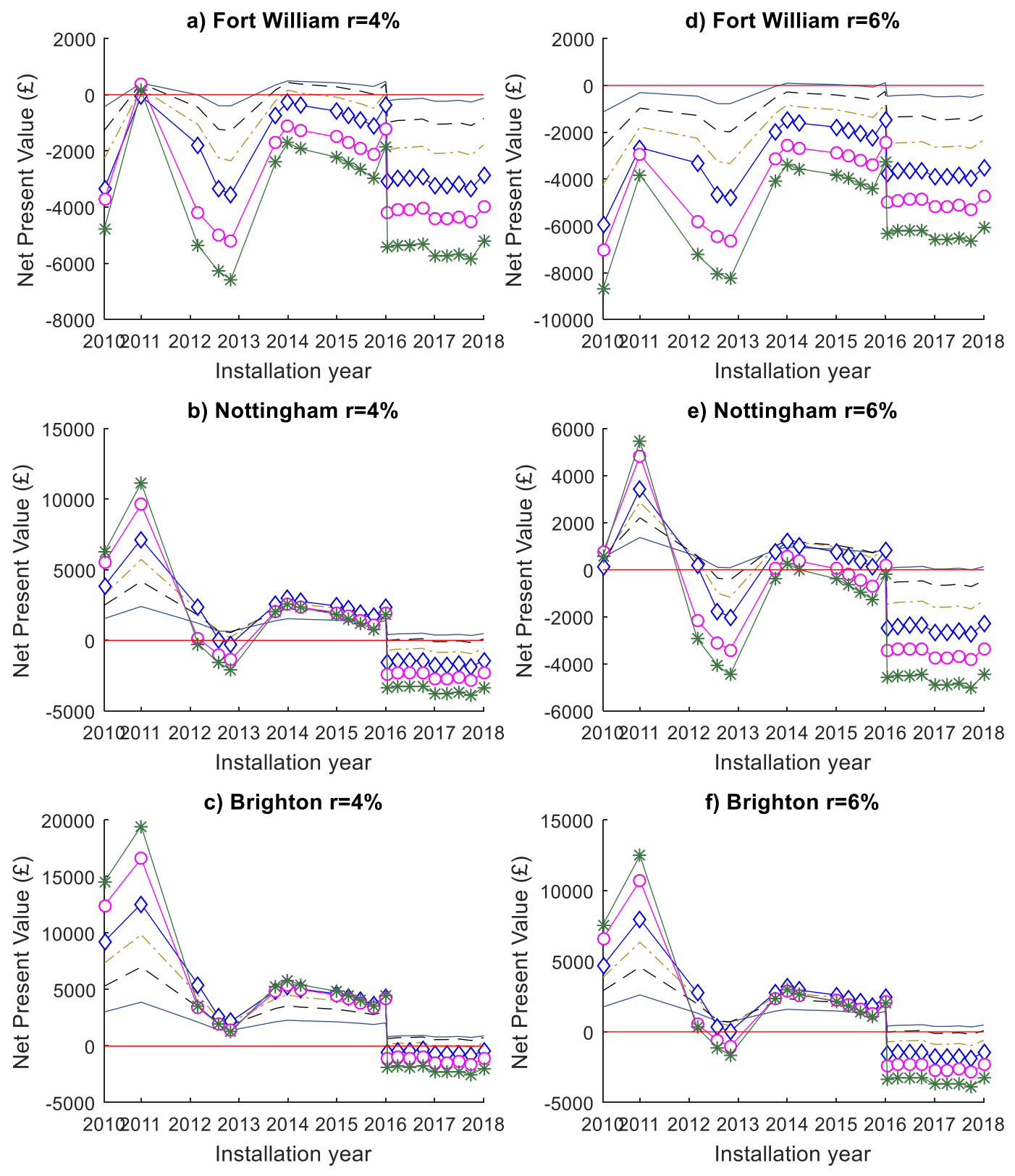

$1 \mathrm{kWp}--2 \mathrm{kWp}-\cdot-3 \mathrm{kWp} \multimap-4 \mathrm{kWp}-\mathrm{O}-5 \mathrm{kWp} \rightarrow-6 \mathrm{kWp}$

Figure 8: Evolution of NPV for domestic PV investment at three locations in the UK under different discount rates

\section{Economic viability of ESS to support domestic PV systems}

The previous section showed significant reduction of PV deployment in the recent couple of years, which has been demonstrated to be mainly attributed to the cutbacks in the government support. This section explores whether energy storage systems, with their ever-decreasing unit cost, could compensate the shrinking profit margin from PV investment.

\subsection{Financial evaluation of PV+ESS investment}

In this section, an investigation of the most profitable combination of PV and ESS is carried out in order to evaluate the potential benefits from additional ESS installation. The ESS size varies from $0 \mathrm{kWh}$ to 
$6 \mathrm{kWh}$ on top of the different PV sizes at three UK locations that were assessed in Section 3. Year 2017 was chosen since it showed the lowest profit from sole PV investment, which is compared with the case in year 2011 when PV was most profitable.

The same information related to the PV system, electricity demand and price, as presented in Section 3, are used in the analysis here. Additional parameters setting and assumptions made for the energy storage are listed in Table 2, where the assumption of 10-year lifetime made for Lithium-ion battery storage was taken from [41]. It can be seen from this table that the power to energy ratio is assumed to be 0.5 in this work, i.e. $P_{E S S_{-} M A X}=-P_{E S S_{-} M I N}=1 / 2 E_{E S S_{-} M A X} / \Delta t$, which is in line with various commerically available ESS products from [42].

Table 2: Parameters and assumptions for ESS

\begin{tabular}{ll}
\hline Parameter & Values \\
\hline$E_{\text {ESS } 0}$ & $1 / 2 E_{\text {ESS_MAX }}$ \\
Power to energy ratio & 0.5 \\
$E_{\text {ESS_MIN }}$ & $0 \mathrm{kWh}$ \\
$E_{E S S_{-} M A X}$ & $0 \mathrm{kWh}$ to $6 \mathrm{kWh}$ with incremental step of $1 \mathrm{kWh}$ \\
ESS lifetime & 10 years \\
\hline
\end{tabular}

The market evolution of unit ESS price from year 2010 to 2028 is collected from [43] [44] [45] and illustrated in Figure 9, covering battery cost, cost for power electronics, and others such as labour cost. According to this figure, the ESS investment cost per $\mathrm{kWh}$ in 2017 has dropped to almost one third of the 2011 value. It is worth pointing out that the lifetime assumption of 10 years for ESS is half of that for PV, and two ESSs are therefore invested during the lifetime of PV in order to truly reflect the potential benefit from ESS via smart energy management. The investment cost for the second ESS needs to be distinguished from the first one. For instance, if the first investment were made in 2017 when the unit ESS price was $£ 412$, then the cost for the second ESS would have been $290 £ / \mathrm{kWh}$ as of 2027. The investment costs contribute towards $C_{i n v}$ in Equation (1), and the yearly cash flow as calculated in Section 2.2 are converted to the present value using a discount rate of $2 \%$.

The maintenance cost of ESS is usually very small and it is not counted towards the cashflow calculation in the ESS economic model here. Similar assumptions on ESS maintenance cost can be found in [46], [47] and [48], which cover battery chemistries used in commercial ESS installations these days (lithium iron phosphate, and lithium manganese cobalt).

The 'fmincon' solver is chosen for this nonlinear optimisation problem, as defined in Section 2.2, due to its good convergence performance [49], and the interior point algorithm is employed here. More details about the algorithm are provided in [50].

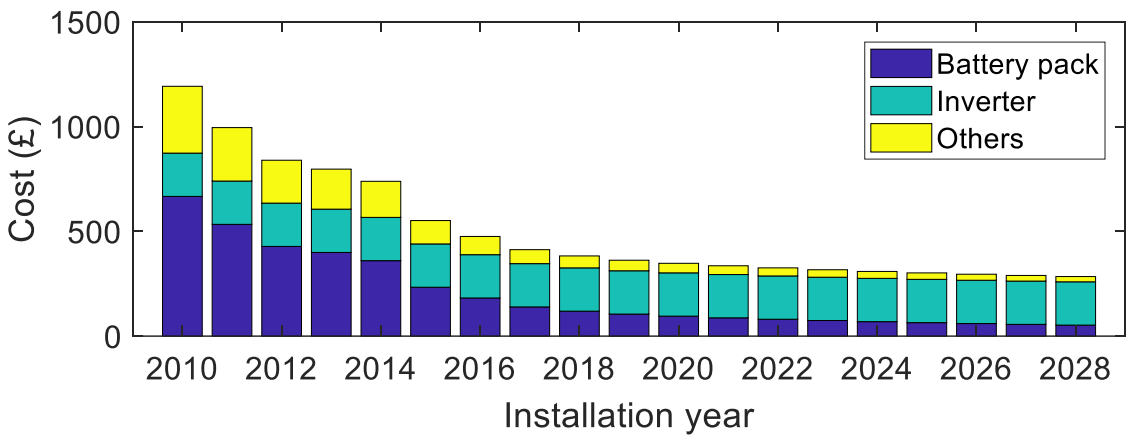

Figure 9: ESS unit cost evolution [43] [44] [45]

\subsection{Results and discussions}

Based on the parameter setting and assumptions made in the previous section, the ESS has been scheduled for optimised daily return of investment, which then optimised the lifetime NPV. Figure 10 illustrates a sample of daily ESS scheduling of the integrated PV+ESS systems, using Brighton as an 
example in year 2017. It can be seen in this figure that the ESS is scheduled to charge from the PV generation excess, which is characterised by higher PV generation than demand profile, and discharge during the evening peak to provide the household demand, with higher charging/discharging rate being provided for larger battery capacity. The ESS charging/discharging rate in Figure 10 does not reach the set bound, which is due to the limitation of the battery sizes. As can be seen in Figure 11, the state of charge of the ESS shows full utilization for all the simulated battery capacity sizes. The economic viability of the PV+ESS systems is evaluated by carrying out the optimisation as such over each operational day.

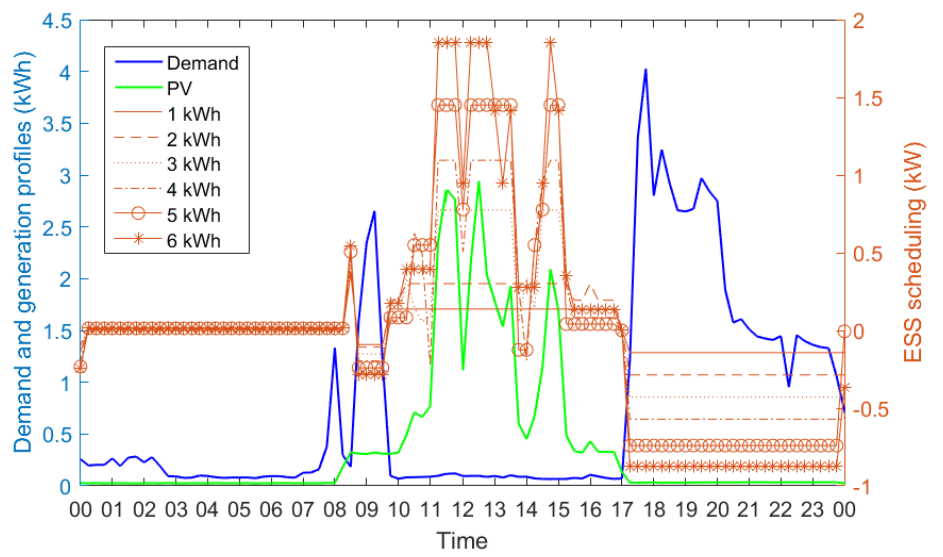

Figure 10: Daily ESS scheduling profiles of integrated PV+ESS systems for Brighton in 2017

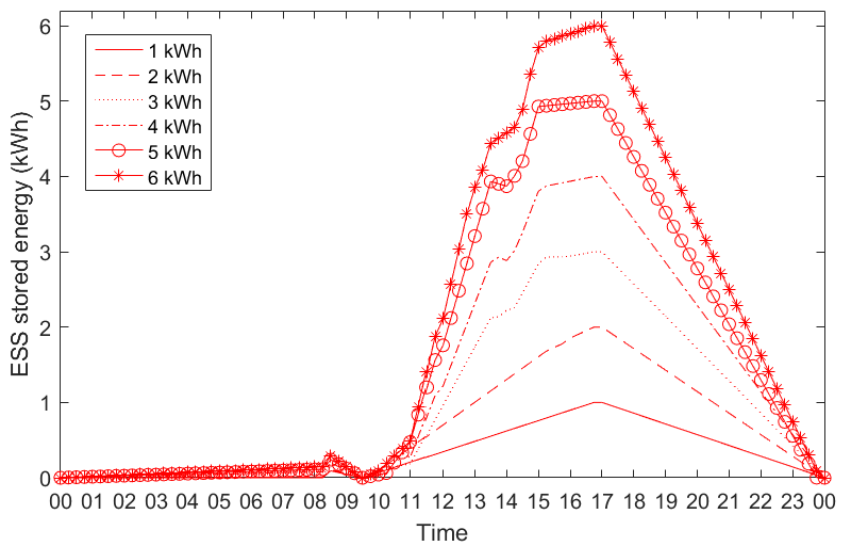

Figure 11: State of charge of the integrated PV+ESS systems for Brighton in 2017

The corresponding NPVs are evaluated for installation year of 2017 and 2011 and are illustrated in Figure 12 and Figure 13, respectively, where the investment combination of different PV and ESS sizes are assessed for the aforementioned three UK locations. The optimal sizing with associated NPV for the investigated cases in this section are summarised in Table 3, which is compared with the results from PV investment obtained in Section 3.3. It could be observed from Figure 12, Figure 13 and Table 3 that the financial improvement of additional ESS installation in 2017 on top of the PV system is limited, i.e. an increase of $£ 557$ and $£ 146$ in NPV (throughout 20 years' lifetime) for Brighton and Nottingham respectively. Fort William remains financially unfavourable for domestic PV renewable deployment. For the case of year 2011, the optimal PV size of $6 \mathrm{~kW}$ corresponds to a relatively low PV self-consumption rate, $32 \%$ for Nottingham for example, which implies the potential for better usage of local renewable generation by the introduction of ESS and therefore better return of investment. However, ESS has been proved to be economically unviable for year 2011 due to its high cost of investment. 
The sensitivity analysis by increasing the discount rate to $4 \%$ and $6 \%$, as implemented in Section 3.4, would lead ESS to be an unprofitable energy option under any year and size of installation. The difference between the results achieved here and those from [12], which demonstrated ESS to be economic viable even when FIT is not considered, could be attributed to the electricity price. The electricity price used in [12] almost doubled the values in this present work, and therefore the former benefited more from self-consumption of local PV production. As the UK's electricity price continues to increase, as projected by the government figures [37], and the battery cost drops due to technology advancement and mass production [44], ESS could demonstrate its financial advance by improving local energy autonomy as well as participating in different energy markets. Trading in these markets offers potential revenue streams, such as network service provision, or trading in electricity wholesale market when FIT is unavailable [12].

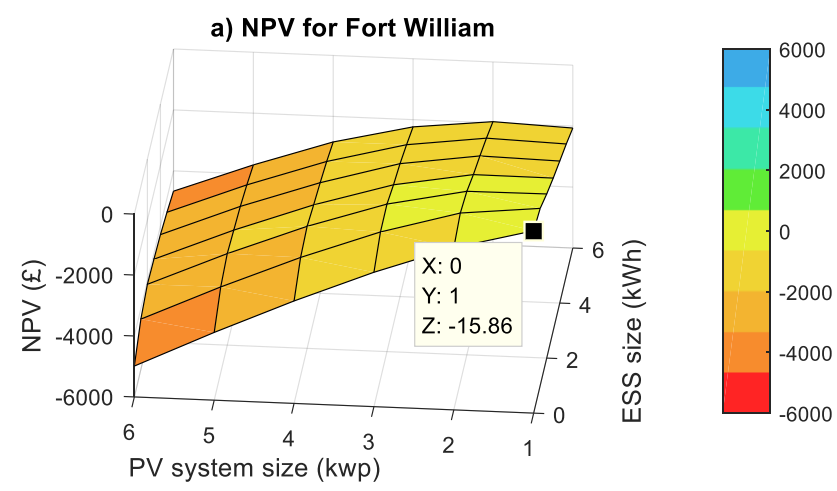

b) NPV for Nottingham

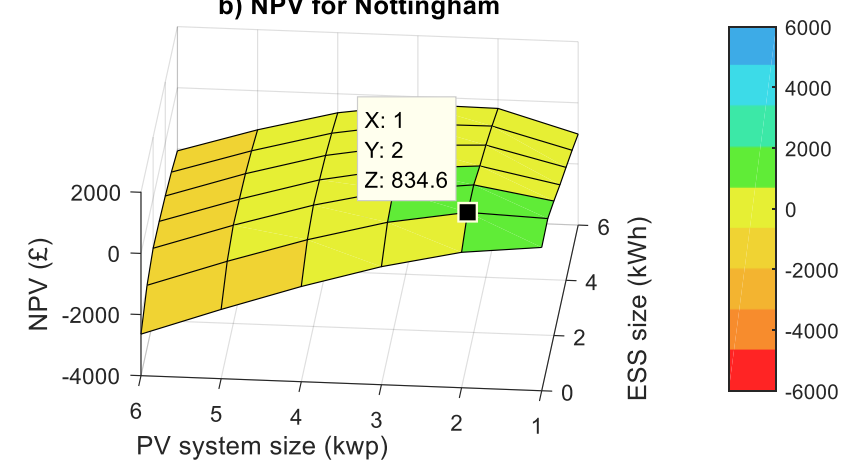

c) NPV for Brighton

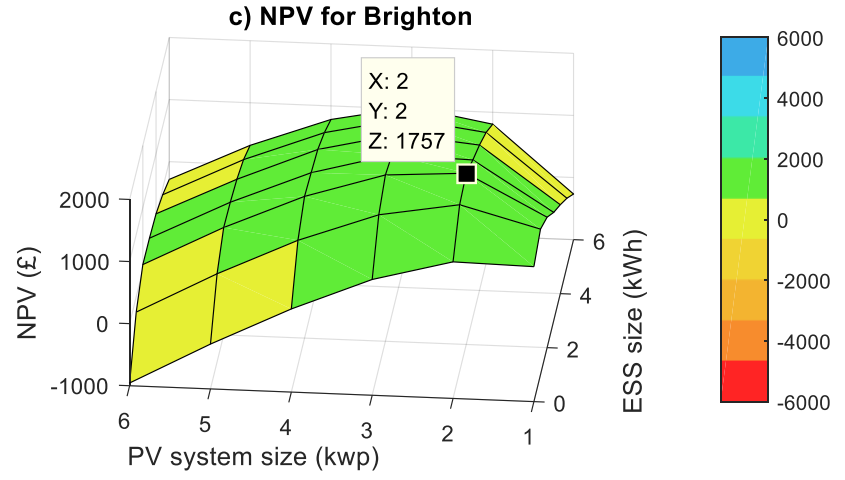




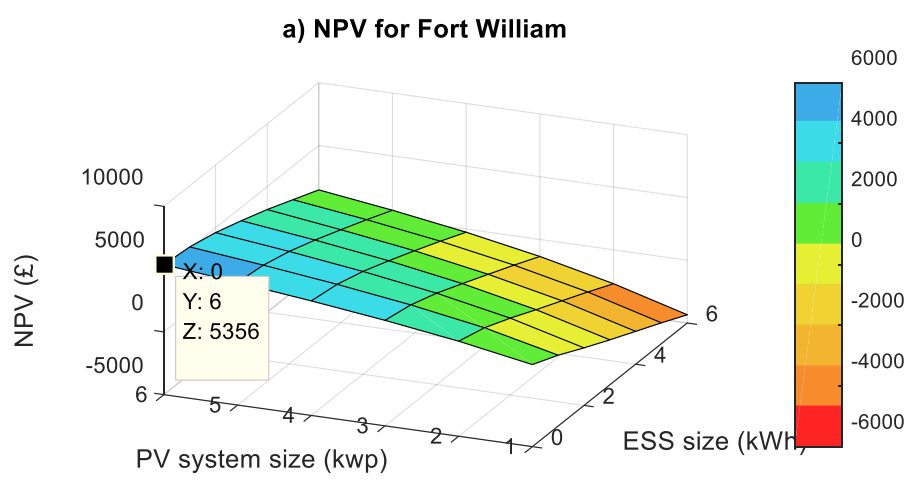

b) NPV for Nottingham

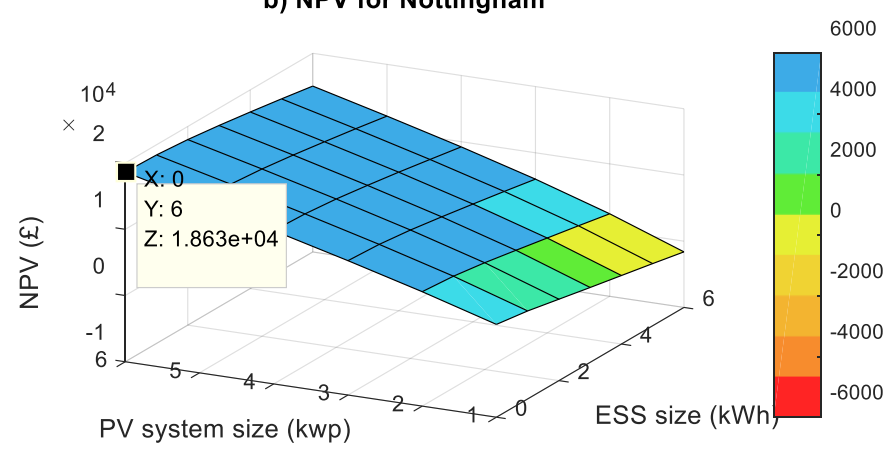

c) NPV for Brighton

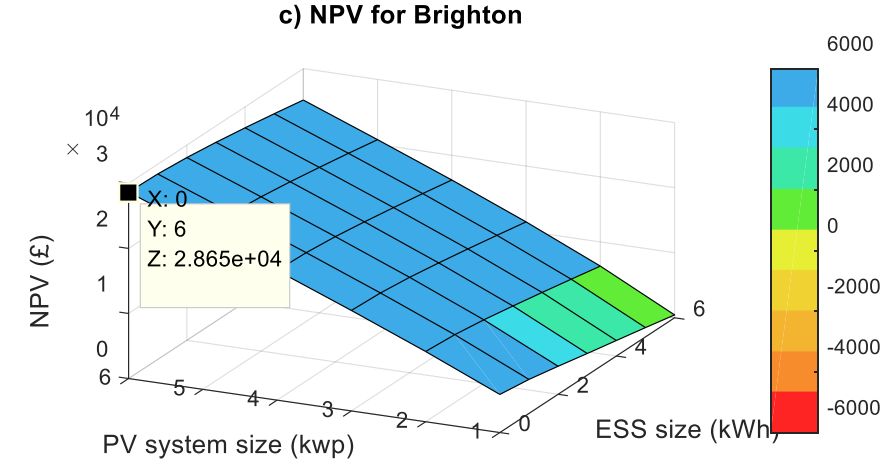

Figure 13: NPV for investment of domestic PV+ESS at three locations in the UK in 2011

Table 3: Optimal sizing and associated NPV for PV+ESS scenario

\begin{tabular}{lllll}
\multicolumn{5}{c}{ Table 3: Optimal sizing and associated NPV for PV+ESS scenario } \\
\hline & Fort William & Nottingham & Brighton \\
\hline 2011 & PV optimal size $(k W p)$ & 6 & 6 & 6 \\
& $P V$ optimal NPV $(£)$ & 5356 & 18630 & 28650 \\
& $P V+$ ESS optimal size $(k W p+k W h)$ & $6+0$ & $6+0$ & $6+0$ \\
& $P V+$ ESS optimal NPV $(£)$ & 5356 & 18630 & 28650 \\
\hline 2017 & $P V$ optimal size $(k W p)$ & 0 & 1 & 2 \\
& $P V$ optimal NPV $(£)$ & 0 & 689 & 1200 \\
& $P V+E S S$ optimal size $(k W p+k W h)$ & $0+0$ & $2+1$ & $2+2$ \\
& $P V+E S S$ optimal $N P V(£)$ & 0 & 835 & 1757 \\
\hline
\end{tabular}

\subsection{Sensitivity of economic return on efficiency}


Energy loss occurs when charging or discharging ESS, including the loss during the energy conversion in the charging device and loss inside the lithium-ion battery. The measured and reported charging efficiency showed a wide range of variation, from the one-way efficiency of the charging/discharging of $12 \%-36 \%$ in [51], to a round-trip efficiency of $80 \%$ as per [52]. To account for the efficiency factor, a sensitivity analysis has been implemented in this section in order to quantify the impact of efficiency on the economic feasibility of ESS. For this purpose, Brighton in year 2017 was chosen as a case study as it was proven to be the most profitable one. A range of one-way efficiency values, between 0.8 and 0.95 with a step of 0.05 , the associated optimal return on investment and optimal sizing are presented in Table 4, which are compared to the benchmark results achieved in Section 4.2.

Table 4: Impact of efficiency on the economic viability for the 2017 Brighton case

\begin{tabular}{lccccc}
\hline One-way efficiency & 1 & 0.95 & 0.9 & 0.85 & 0.8 \\
Round-trip efficiency & 1 & 0.9 & 0.81 & 0.72 & 0.64 \\
$\begin{array}{l}\text { Most profitable configuration } \\
(k W p+k W h)\end{array}$ & $2+2$ & & & $2+1$ & \\
$N P V(£)$ & 1,757 & 1,658 & 1,607 & 1,550 & 1,487 \\
Benefit of ESS integration $(£)$ & 557 & 458 & 407 & 350 & 287 \\
\hline
\end{tabular}

It can be seen that all of the investigated efficiency values demonstrated the investment to be profitable. Even in the worst-case scenario of a round-trip efficiency of 0.64, ESS led to an additional benefit of $£ 287$ on top of the sole investment in PV. As expected, the return on investment to decrease as the efficiency drops, which is proved by the results shown in Table 4.

\section{Economic viability of EV to support domestic PV systems}

The benefits brought by ESS together with domestic PV installation have been shown to be limited and highly dependent on location and year of PV installation. EVs are on the verge of massive global deployment, reinforced by the bans on internal combustion engine (ICE) vehicle sales around the globe [53], which indicate a more prominent role of EVs in energy management for future domestic systems. An EV battery, which can serve domestic energy management as an ancillary function additional to transportation, is investigated as an alternative to ESS for complementing PV generation. Year 2017 and 2011 are chosen in this section for a like-for-like analysis with the ESS performance.

\subsection{Financial evaluation of $P V+E V$ investment}

EV in this case is regarded as energy storage when being available at home, which allows energy coordination with local PV generation via Vehicle to Home (V2H). Real-life EV usage patterns with 10-minute resolution from the UK Time of Use Survey [54] have been used in this work. The associated probability of EV availability at home is illustrated in Figure 14 for both weekdays and weekends. 


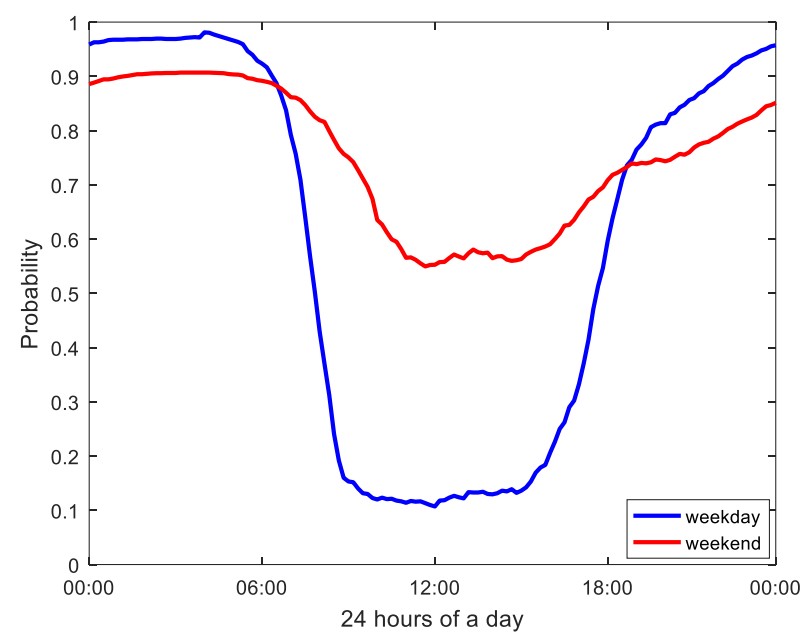

Figure 14: Averaged probability of EV home availability for weekdays and weekends [54]

$\mathrm{EV}$ energy exchange only in the form of $\mathrm{V} 2 \mathrm{H}$ is analysed in this section since the objective is to assess the economic effectiveness of $\mathrm{V} 2 \mathrm{H}$; EV charging related to normal transportation purpose with associated degradation is not considered here. For a fair comparison with the scenarios of PV+ESS, the same battery sizes as the ESS case are investigated as shown in Table 5, where the allocated battery capacity can be fully used for V2H purpose.

According to [55], Nissan Leaf is the most popular battery electric vehicle model in the UK, and hence it is studied here. The UK National Travel Survey data shows that on average $90 \%$ of the UK drivers travel less than 25 miles daily [56], which results in daily charging requirement of $3.75 \mathrm{kWh}$ by considering a battery capacity to mileage ratio of $0.15 \mathrm{kWh} / \mathrm{mile}$. Based on these considerations, the choice of using $18 \mathrm{kWh}$ out of the $24 \mathrm{kWh}$ available capacity in the EV (Nissan Leaf) battery for transportation purpose will largely suffice for the transportation needs of the average UK driver.

Table 5: Parameters and assumptions for EV

\begin{tabular}{ll}
\hline Parameter & Values \\
\hline$P_{E V}$ & {$[-3 \mathrm{~kW}, 3 \mathrm{~kW}]$} \\
$E_{E V 0}$ & $1 / 2 E_{E V \_M A X}$ \\
$E_{E V_{-} M I N}$ & $0 \mathrm{kWh}$ \\
$E_{E V \_} M A X$ & $0 \mathrm{kWh}$ to $6 \mathrm{kWh}$ with incremental step of $1 \mathrm{kWh}$ \\
EV charger cost & $£ 500$ (see text for further explanations) \\
EV charger lifetime & 10 years \\
$a_{1}$ & 0.0015 \\
$a_{2}$ & 0.0635 \\
\hline
\end{tabular}

The parameters setting and assumptions made for the energy storage are listed in Table 5. The cost of a bi-directional charger is still quite cryptic, with available quotations and discussed prices so far ranging from $£ 600$ to $£ 3500$ [57]. Its cost is assumed here to be $£ 1000$ with a lifetime of 10 years. Taking into account of the UK government grant that covers up to $75 \%$ of the installation cost of a domestic charger or up to $£ 500$ [58], the final investment cost for the bi-directional charger is $£ 500$. The upper bound of charging/discharging rate of $[-3 \mathrm{~kW}, 3 \mathrm{~kW}]$ is in line with the rating for a domestic EV charger.

As mentioned in Section 2.3, the operational cost is due to battery degradation as well as the energy consumption. The battery degradation cost is achieved by setting experiments using commercial EV battery cells, at various exchange rates that correspond to those of commercially available standard EV 
charger, i.e. $3 \mathrm{~kW}, 7 \mathrm{~kW}$ and $22 \mathrm{~kW}$. The cost in terms of $£ / \mathrm{kWh}$ for each respective rate is calculated by dividing the battery cost by the associated lifetime energy throughput, assuming $80 \%$ of usable battery capacity being the end of mobility life. The cost of commercial Lithium-ion cells as of 2017 of $\$ 200 / \mathrm{kWh}(£ 150 / \mathrm{kWh})$ is used in this work [59]. Once the experiment data is achieved at the abovementioned charging rates, a linear relationship between degradation cost and the exchange rate can be established. The associated parameter fitting for Equation (12) is presented in Table 5. In addition, the maintenance cost for EV battery is assumed to be negligible here.

Since the main purpose of the EV battery is to serve the transportation, while the vehicle to home $(\mathrm{V} 2 \mathrm{H})$ is regarded as an ancillary function of EV, the capital cost of EV battery is regarded as the investment for transportation rather than domestic energy management. The extra battery degradation of EV battery cost due to V2H, i.e. energy exchange with PV generation and household demand, needs to be counted in the cash flow and is calculated using Equation (12). This needs to be distinguished from cost calculation of ESS in the scenario of PV+ESS, where the ESS is invested solely for the purpose of domestic energy management. Therefore, the capital investment cost of ESS is included in the associated cash flow calculation to incorporate the battery degradation throughout its lifetime.

It is worth noting that the battery capacity degradation has not been considered in the simulation for either the EV or ESS cases. Such assumptions were made by taking into account the warranty of commercial products. As reference [42] indicates, various commercial ESS solutions provide warranties over the lifetime of the battery, which in most cases is 10 years (same as the lifetime considered in our work), or 6,000-10,000 full cycles. Similar warranty is also available for the EV battery. According to the official Nissan (car model used in this work) website, [60], a 5-year or 60,000 miles state of health is guaranteed for the $24 \mathrm{kWh}$ Nissan Leaf.

As can be seen from the ESS and EV scheduling results, roughly one charging/discharging cycle is incurred per day under normal operating conditions. The projected lifetime cycle as such is well within the warranty figure, for both EV battery and ESS. We therefore assume that the capacity of EV battery and ESS remained unaltered in the simulation.

\subsection{Results and discussions}

Following the settings in the previous section, the financial effectiveness for the respective EV battery sizes, as storage solution, are evaluated in combination with various PV installed capacities from $1 \mathrm{kWp}$ to $6 \mathrm{kWp}$. The optimal EV charging scheduling is depicted in Figure 15 for the same day as shown in Figure 10. Two observations on the difference between EV and ESS scheduling can be made by comparing these two figures. First, the EV unavailability (cyan diamonds of value 0 ) has restrained the participation of EV battery in the energy exchange, i.e. such service can only be provided during home parking period. Consequently, the EV was less charged than the ESS during the PV excess period and is mostly unavailable to support the evening peaks. The other observation is the difference in the scheduled rate of ESS and EV battery, which is due to the study setting. The former assumes ESS rate to be proportional to the battery capacity, while in the latter case the EV battery rate is variable but capped at $3 \mathrm{~kW}$ for all the modelled battery sizes as per the technical specification of the EV charging device.

It can be seen from Figure 15 that higher charging rate was scheduled for larger EV battery sizes from $7 \mathrm{pm}$ to midnight, in order to supply the evening demand, where larger EV battery sizes also discharged at higher rates. As such, higher battery sizes, in this case, $6 \mathrm{kWh}$, offer better energy management and therefore potentially lead to the optimal return on investment. The associated state of charging for the investigated EV battery sizes are illustrated in Figure 16, which shows that each of the battery size is fully used to optimize the domestic energy management. The batteries with different sizes are fully charged during PV generation excess and then they are completely utilized to provide the evening demand. The EV charging profiles in Figure 15 generally exhibit higher rates than the ESS charging results in Figure 10, which is to compensate the PV energy that was missed out during the EV 
unavailability from $3 \mathrm{pm}$ to $5 \mathrm{pm}$. Likewise, the discharging rate is also higher in the EV case than the ESS results.

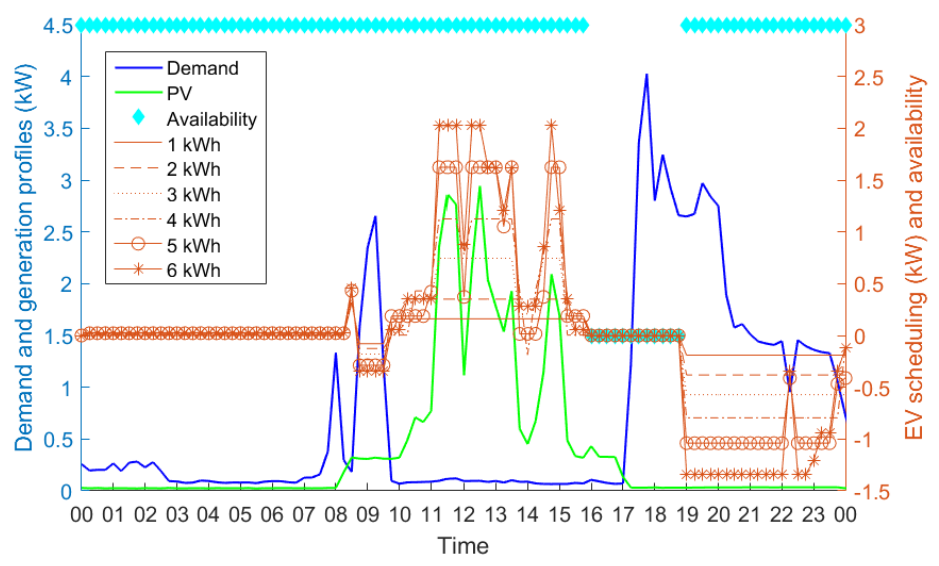

Figure 15: Daily EV scheduling profiles of integrated PV+EV systems for Brighton in 2017

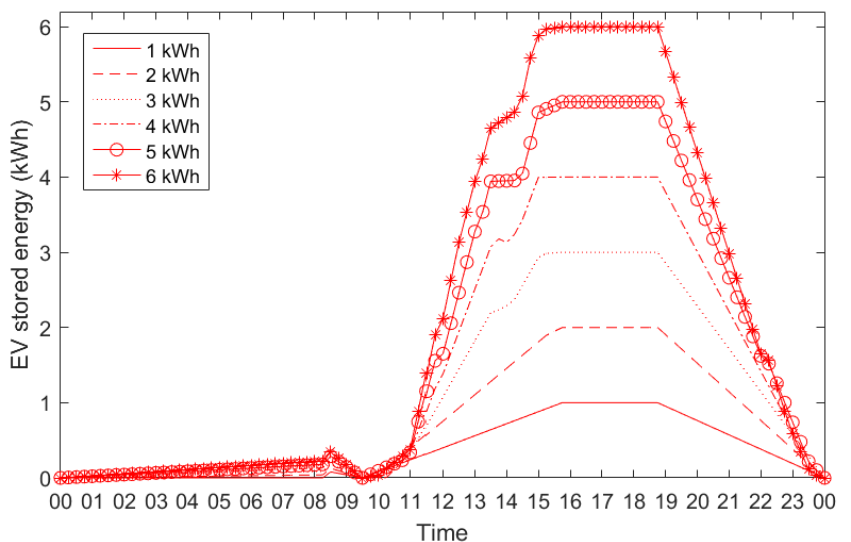

Figure 16: State of charge of the integrated PV+EV systems for Brighton in 2017

The solutions to the optimisation problem formulated in Section 2.3 leads to the optimal sizing of $\mathrm{PV}+\mathrm{EV}$ scenario for year 2017 is summarised in Table 6. Fort William remains economically unviable for any household energy solutions. EV proves to be less profitable than ESS by comparing the optimal NPV of Nottingham and Brighton in Table 6 with those in Table 3. In fact, the combination of PV+EV is worse off than sole investment on PV. Using EV battery as a storage solution has been demonstrated to be not viable in this case.

It can be observed in Figure 14 that the EV availability was rather low during the PV generation period, in particular for the weekdays, which indicates that $\mathrm{EV}$ would not make full use of the solar generation from domestic PV systems. This could also be the reason why EV is less competitive compared with ESS. A further assessment is then carried out assuming 100\% EV availability, in which case EV serves essentially as a stationary energy storage. The corresponding results are given in Table 6 and show improvement in NPV for Nottingham and Brighton, compared with when EV is used for normal transportation, however it is still not as beneficial as the ESS. This is due to the higher equivalent EV battery capital cost than that of ESS.

For example, the optimal PV+ESS combination in year 2017 features at $2 \mathrm{kWp}$ and a $1 \mathrm{kWh}$ respectively in Nottingham, where the capital cost of ESS is $£ 469$ in 20 years. On the other hand, battery degradation cost for EV, as calculated in Equation (12), following the same cycle patterns leads to $£ 620$ in 20 years. The combination of this battery degradation cost and additional investment cost for the bi- 
directional charger have turned down the opportunity of EV being a viable alternative to ESS for domestic energy solution. In future, however, EVs may provide a suitable option for domestic applications when the price of EV batteries as well as the bi-directional chargers drop.

Table 6: Optimal sizing and associated NPV for PV+EV scenario for year 2017

\begin{tabular}{|c|c|c|c|}
\hline & Fort William & Nottingham & Brighton \\
\hline$P V+E V$ optimal size $(k W p+k W h)$ & $0+0$ & $1+6$ & $2+6$ \\
\hline$P V+E V$ optimal NPV $(£)$ & 0 & 250.35 & 836.15 \\
\hline \multicolumn{4}{|c|}{ with $100 \%$ EV availability } \\
\hline$P V+E V$ optimal size $(k W p+k W h)$ & $0+0$ & $1+6$ & $2+6$ \\
\hline$P V+E V$ optimal NPV $(£)$ & 0 & 346 & 1144 \\
\hline
\end{tabular}

\section{Conclusions}

This work has assessed the investment attractiveness for domestic energy solutions, namely PV, energy storage and electric vehicles for different installation sizes and year of installation, as well as different geographical locations. FIT has been identified as the driving factor for return of domestic PV investment. In the UK case study, the most profitable year of PV installation was 2011, where Brighton showed more than 5 times financial return compared with that of Fort William. The unviability of PV investment was demonstrated since year 2016 due to a significant drop in FIT rate. Even the well-sited PV projects were shown to be merely economically viable at selected choice of PV sizes.

The presented approach of economic evaluation for PV investment in this work has been verified by the associated annual national PV deployment capacity. The shrinking profit margin from PV investment in recent years can be compensated by installing additional ESS to make better use of the PV generation, but demonstrated to be only by limited amount and only for areas with sufficient solar irradiation. EV at the moment has been proved to be financially unviable for use in existing domestic PV systems, due to the high capital cost of the bi-directional charger, EV battery degradation cost, and the low home availability of EV for V2H provision. However, from the decreasing trend in battery costs, increasing energy demand and tariffs, a brighter economic future is foreseen for ESS and EVs. As pointed out in this paper, battery storage technologies are substantially cheaper than in the last decade and projections show further cost reductions ahead due to mass production and technology advancement. This will contribute to a wider, more affordable and sustainable implementation of battery storage in a future energy landscape dominated by renewable energy. The methodology of economic evaluation described in this paper can be easily implemented in other FIT adopted countries and regions, such as those hold different climate, electricity price or consumption patterns, by using the location specific parameters.

\section{Acknowledgements}

This work has been supported by EU - Interreg North Sea Region programme - Smart, clean Energy and Electric Vehicles for the City (SEEV4-City) project J-No.: 38-2-23-15.

\section{List of References}

[1] IRENA, The Power to Change: Solar and Wind Cost Reduction Potential to 2025, June 2016.

[2] REN21, Renewables 2018 global status report, Tech. rep., Renewable Energy Policy Network for $21^{\text {st }}$ Century, 2018.

[3] Annual Report 2014, International Energy Agency - Photovoltaic Power Systems Programme (IEA-PVPS), May 2015.

[4] Poruschi, L., Ambrey, C.L. and Smart, J.C., Revisiting feed-in tariffs in Australia: a review. Renewable and Sustainable Energy Reviews, 82, pp.260-270, 2018. 
[5] Feed-In Tariff (FIT) rates, [online] Available at: https://www.ofgem.gov.uk/environmentalprogrammes/fit/fit-tariff-rates?page=3\#block-views-publications-and-updates-block [accessed 23/07/2018]

[6] Photovoltaics: investment attractiveness for Belgian households, Energy outlook, Jan 2016. [online] Available at: http://energy.sia-partners.com/photovoltaics-investment-attractivenessbelgian-households [accessed 17/05/2018]

[7] Bakhshi, R. and Sadeh, J., Economic evaluation of grid-connected photovoltaic systems viability under a new dynamic feed-in tariff scheme: A case study in Iran. Renewable Energy, 2018; 119, pp.354-364.

[8] Akter, M.N., Mahmud, M.A. and Oo, A.M., Comprehensive economic evaluations of a residential building with solar photovoltaic and battery energy storage systems: An Australian case study. Energy and Buildings, 2017, 138, pp.332-346.

[9] Audenaert, A., De Boeck, L., De Cleyn, S., Lizin, S. and Adam, J.F., An economic evaluation of photovoltaic grid connected systems (PVGCS) in Flanders for companies: A generic model. Renewable Energy, 2010, 35(12), pp.2674-2682.

[10] Pillai, G.G., Putrus, G.A., Georgitsioti, T. and Pearsall, N.M., Near-term economic benefits from grid-connected residential PV (photovoltaic) systems. Energy, 2014, 68, pp.832-843.

[11] Uddin, K., Gough, R., Radcliffe, J., Marco, J. and Jennings, P., Techno-economic analysis of the viability of residential photovoltaic systems using lithium-ion batteries for energy storage in the United Kingdom. Applied Energy, 206, pp.12-21, 2017

[12] Hoppmann J., Volland J., Schmidt T.S., Hoffmann V.H., The economic viability of battery storage for residential solar photovoltaic systems - A review and a simulation model, Renewable and Sustainable Energy Reviews, 39, pp. 1101-1118, 2014.

[13] McKenna, R., Merkel, E. and Fichtner, W., Energy autonomy in residential buildings: a technoeconomic model-based analysis of the scale effects. Applied Energy, 2017, 189, pp.800-815.

[14] Phipps, W. and Sivadas, D., Economic evaluation of a grid-connected PV system at Otago Polytechnic. In Electrical, Computer and Communication Technologies (ICECCT), 2017 Second International Conference on, IEEE, pp. 1-6, 2017.

[15] Assunção, A., Moura, P.S. and de Almeida, A.T., 2016. Technical and economic assessment of the secondary use of repurposed electric vehicle batteries in the residential sector to support solar energy. Applied energy, 181, pp.120-131.

[16] Truong, C., Naumann, M., Karl, R., Müller, M., Jossen, A. and Hesse, H., 2016. Economics of residential photovoltaic battery systems in Germany: The case of Tesla's Powerwall. Batteries, 2(2), p.14.

[17] Cucchiella, F., D'Adamo, I. and Gastaldi, M., 2017. The economic feasibility of residential energy storage combined with PV panels: The role of subsidies in Italy. Energies, 10(9), p.1434.

[18] De Schepper, E., Van Passel, S. and Lizin, S., 2015. Economic benefits of combining clean energy technologies: the case of solar photovoltaics and battery electric vehicles. International journal of energy research, 39(8), pp.1109-1119.

[19] Drude L., Pereira Junior L. C. and Rüther R., Photovoltaics (PV) and electric vehicle-to-grid (V2G) strategies for peak demand reduction in urban regions in Brazil in a smart grid environment, Renewable Energy, Vol. 68, pp. 443-451, 2014.

[20] Kumar K.N., Sivaneasan B., Cheah P.H., So P.L. and Wang D.Z.W., V2G Capacity Estimation Using Dynamic EV Scheduling, IEEE Transactions on Smart Grid, Vol. 5, No. 2, pp. 10511060, March 2014.

[21] Lamedica R., Teodori S., Carbone G. and Santini E., An energy management software for smart buildings with V2G and BESS, Sustainable Cities and Society, Vol. 19, pp. 173-183, 2015 . 
[22] Alam M.J.E., Muttaqi K.M. and Sutanto D., Effective Utilization of Available PEV Battery Capacity for Mitigation of Solar PV Impact and Grid Support With Integrated V2G Functionality, IEEE Transactions on Smart Grid, Vol. 7, No. 3, pp. 1562-1571, May 2016.

[23] Laurischkat, K. and Jandt, D., 2018. Techno-economic analysis of sustainable mobility and energy solutions consisting of electric vehicles, photovoltaic systems and battery storages. Journal of cleaner production, 179, pp.642-661.

[24] Abdelhamid, M., Singh, R., Qattawi, A., Omar, M. and Haque, I., 2014. Evaluation of on-board photovoltaic modules options for electric vehicles. IEEE Journal of Photovoltaics, 4(6), pp.1576-1584.

[25] Abdelhamid, M., Pilla, S., Singh, R., Haque, I. and Filipi, Z., 2016. A comprehensive optimized model for on-board solar photovoltaic system for plug-in electric vehicles: energy and economic impacts. International Journal of Energy Research, 40(11), pp.1489-1508.

[26] Lin, C.H., Hsieh, W.L., Chen, C.S., Hsu, C.T., Ku, T.T. and Tsai, C.T., Financial analysis of a large-scale photovoltaic system and its impact on distribution feeders. IEEE Transactions on Industry Applications, 47(4), pp.1884-1891, 2011.

[27] Lacey G., Putrus G. and Bentley E., Smart EV charging schedules: supporting the grid and protecting battery life, in IET Electrical Systems in Transportation, 7 (1), pp. 84-91, 2017

[28] Feed-in Tariffs, [online] Available at: http://www.energysavingtrust.org.uk/renewableenergy/electricity/solar-panels/feed-tariffs [accessed 23/07/2018]

[29] Feed-in Tariff Scheme, Renewable energy consumer code, [online], available at: https://www.recc.org.uk/pdf/feed-in-tariff-scheme-guidance-for-consumers.pdf [accessed 19/12/2019]

[30] Energy networks association, Engineering Recommendation G83, Issue 2 Amendment 1 July 2018.

[31] Solar photovoltaic (PV) cost data, [online] Available at: https://www.gov.uk/government/statistics/solar-pv-cost-data [accessed 25/06/2018]

[32] UK solar beyond subsidy: the transition, Renewable Energy Association, July 2015.

[33] Burnett, D., Barbour, E. and Harrison, G.P., The UK solar energy resource and the impact of climate change. Renewable Energy, 71, pp.333-343, 2014

[34] Photovoltaic Geographical Information System - Interactive Maps, [online] Available at: http://re.jrc.ec.europa.eu/pvgis/apps4/pvest.php?lang=en\&map=europe [accessed 26/06/2018]

[35] Energy Consumption in the UK 2017 update, Department for Business, Energy \& Industrial Strategy, 2017.

[36] Sub-national electricity and gas consumption statistics: analysis tool, Department for Business, Energy \& Industrial Strategy, [online] Available at: https://www.gov.uk/government/publications/sub-national-electricity-and-gas-consumptionstatistics-analysis-tool [accessed 30/07/2018]

[37] Average annual domestic electricity bills for UK countries, [UK] Department for Business, Energy \& Industrial Strategy, March 2018.

[38] Vartiainen E., Masson G., and Breyer C., PV LCOE in Europe 2014-30, 10.13140/RG.2.1.4669.5520, 2015

[39] Department for Energy and Climate Change, Periodic Review of FITs 2015, Dec 2015.

[40] Solar photovoltaics deployment, [online] Available at: https://www.gov.uk/government/statistics/solar-photovoltaics-deployment [accessed 31/07/2018]

[41] Barcellona S., Piegari L., Musolino V. and Ballif C., Economic viability for residential battery storage systems in grid-connected PV plants, in IET Renewable Power Generation, 2018, vol. 12, no. 2, pp. 135-142.

[42] SOLAR BATTERIES \& STORAGE, [online] Available at: https://nakedsolar.co.uk/storage/

[43] Chediak M.,Bloomberg energy finance, [online], Available at: https://www.bloomberg.com/news/articles/2018-03-08/the-battery-will-kill-fossil-fuels-it-sonly-a-matter-of-time [accessed 30/07/2018] 
[44] IRENA, Electricity Storage and Renewables: Costs and Markets to 2030, International Renewable Energy Agency, Abu Dhabi, 2017

[45] Inverters, Available at: http://www.photonicuniverse.com/en/catalog/list/page/4/category/inverters [accessed 30/07/2018]

[46] What regular maintenance is required of batteries used in solar systems? available at: https://www.solarpowerworldonline.com/2018/12/what-regular-maintenance-is-required-ofbatteries-used-in-solar-systems/ [accessed 04/04/2020]

[47] S. Anuphappharadorn, S. Sukchai, C. Sirisamphanwong, and Ni. Ketjoy, Comparison the economic analysis of the battery between lithium-ion and lead-acid in PV stand-alone application, Energy Procedia, vol. 56, 2014, pp. 352-358.

[48] G. Albright, J. Edie and S. Al-Hallaj, A Comparison of Lead Acid to Lithium-ion in Stationary Storage Applications, Published by AllCell Technologies LLC March 2012.

[49] Wang Y., Infield D., and Gill S., Smart charging for electric vehicles to minimize charging cost, Proceedings of the Institution of Mechanical Engineers, Part A: Journal of Power and Energy, pp.1-15, 2016

[50] Byrd R.H., Hribar M.E., Nocedal J., SIAM Journal on Optimisation, 1999.

[51] E. Apostolaki-Iosifidou, P. Codani and W. Kempton, Measurement of power loss during electric vehicle charging and discharging, Energy, vol 127, pp. 730-742, 2017.

[52] Battery roundtrip efficiency, HOMER Pro 3.13, [online] Available at: https://www.homerenergy.com/products/pro/docs/latest/battery_roundtrip_efficiency.html [accessed 20/12/2019]

[53] Witkamp B., Van Gijlswijk E., Bolech M., Coosemans T. and Hooftman N., The transition to a Zero Emission Vehicles fleet for cars in the EU by 2050 : Pathways and impacts: An evaluation of forecasts and backcasting the COP21 commitments, European Alternative Fuel Observatory, 2017.

[54] The United Kingdom 2000 Time Use Survey, National Statistics Technical Report, 2003.

[55] Electric car market statistics, available at: https://www.nextgreencar.com/electric-cars/statistics/ [accessed 20/12/2019]

[56] National Travel Survey, available at: https://www.gov.uk/government/collections/nationaltravel-survey-statistics [accessed 20/12/2019]

[57] Gough R., Dickerson C., Rowley P. and Walsh C., Vehicle-to-grid feasibility: A technoeconomic analysis of EV-based energy storage, Applied Energy, 192, pp. 12-23, 2017

[58] Electric Vehicle Homecharge Scheme, [online] Available at: https://www.gov.uk/government/collections/government-grants-for-low-emissionvehicles\#electric-vehicle-homecharge-scheme [accessed 20/08/2018]

[59] Global EV Outlook 2017-Two million and counting, CLEAN ENERGY MINISTERIAL, International Energy Agency, France, 2016.

[60] Nissan Warranty, available at: https://www.nissan.co.uk/ownership/nissan-car-warranties.html [accessed 30/03/2020] 